\title{
Setting a best practice for determining the EGR rate in hydrogen internal combustion engines
}

\author{
S. Verhelst, J. Vancoillie, K. Naganuma, M. De Paepe, J. Dierickx, Y. \\ Huyghebaert \\ Ghent University, Department of Flow, Heat and Combustion Mechanics, \\ Sint-Pietersnieuwstraat 41 B-9000 Gent, Belgium \\ T. Wallner \\ Argonne National Laboratory, Argonne, IL, USA
}

\section{Abstract}

Exhaust gas recirculation (EGR) is an effective way to reduce $N O_{x}$-emissions and increase the efficiency of hydrogen-fuelled internal combustion engines. Knowledge of the exact amount of EGR is crucial to understand the effects of EGR. As the exhaust gas flow is pulsating and chemically aggressive, the flow rate is typically not be measured directly and has to be derived from other quantities. For hydrocarbon fuels, the EGR rate is generally calculated from a molar $\mathrm{CO}_{2}$ balance, but for hydrogen engines this obviously cannot be used as there are no $\mathrm{CO}_{2}$ emissions, and consequently no standard practice has been established. This work considers three methods to calculate the amount of EGR in a hydrogen engine. The first one is based upon a volume balance in the mix-

${ }_{20}$ ing section of exhaust gases and fresh air. The second and third method use a molar balance of $\mathrm{O}_{2}$ and $\mathrm{H}_{2} \mathrm{O}$ respectively in this mixing section. The three methods are developed and tested for their accuracy with an error analysis. Additionally, the methods are applied to an experimental dataset gathered on a single cylinder hydrogen engine. Both the theoretical analysis and the exper-

25 imental results confirm the method based on an $\mathrm{O}_{2}$ molar balance as the most accurate one. The least practical method is the one based on an $\mathrm{H}_{2} \mathrm{O}$ balance as it requires additional relative humidity sensors and is less accurate than the others.

Keywords: internal combustion engine, hydrogen, EGR measurement, error 30 analysis 


\section{Nomenclature}

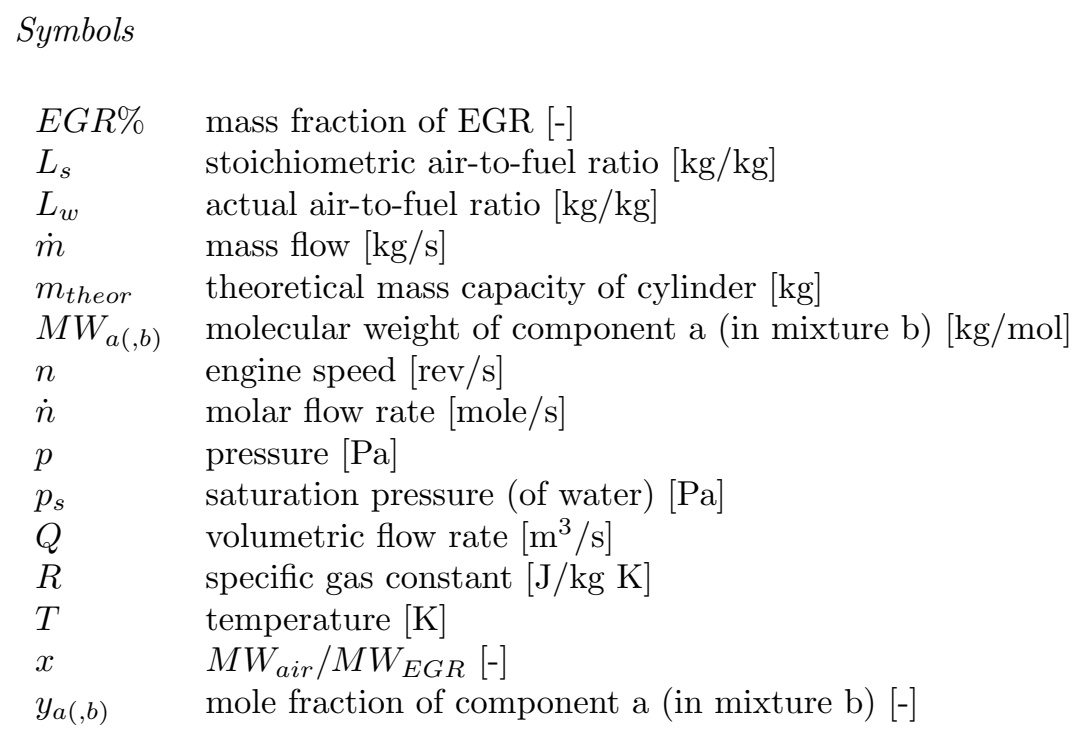

Greek symbols

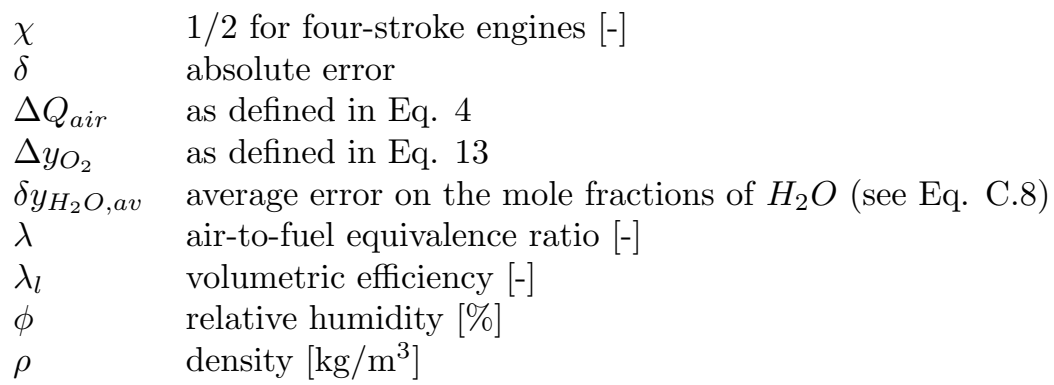

Subscripts

EGR recirculated exhaust gas

air air

$\mathrm{H}_{2} \quad$ hydrogen

mix intake mixture of fresh air and EGR

$\mathrm{O}_{2} \quad$ oxygen

non $-\mathrm{O}_{2}$ all gas components except oxygen

dry all gas components except $\mathrm{H}_{2} \mathrm{O}$ 


$\begin{array}{ll}\text { ABDC } & \text { after bottom dead centre } \\ \text { ATDC } & \text { after top dead centre } \\ \text { BBDC } & \text { before bottom dead centre } \\ \text { BTDC } & \text { before top dead centre } \\ \text { BMEP } & \text { brake mean effective pressure } \\ \text { DC } & \text { direct current } \\ \text { ECU } & \text { engine control unit } \\ \text { EGR } & \text { exhaust gas recirculation } \\ \text { EVC } & \text { exhaust valve closing } \\ \text { EVO } & \text { exhaust valve opening } \\ H_{2} \text { ICE } & \text { hydrogen internal combustion engine } \\ \text { ICE } & \text { internal combustion engine } \\ \text { IVC } & \text { intake valve closing } \\ N O_{x} & \text { oxides of nitrogen } \\ \text { PFI } & \text { port fuel injection } \\ \text { RH } & \text { relative humidity } \\ \text { SI } & \text { spark ignition } \\ \text { WOT } & \text { wide open throttle }\end{array}$

\section{Introduction}

Hydrogen is widely regarded as an attractive alternative for fossil fuels with the possibility of great efficiency and low emissions [1,2]. The most mature technology using hydrogen as an energy carrier is the internal combustion en40 gine (ICE). To be fully competitive with fossil fuels, a hydrogen fuelled ICE must be able to achieve a comparable performance. However, due to the lower volumetric energy density, a port fuel injection (PFI) hydrogen engine operating stoichiometric at wide open throttle (WOT) has a power deficit of about $15 \%$ compared to a gasoline engine [3]. Several strategies have been developed to

45 bridge that power deficit and increase engine efficiency, including supercharging and direct injection, sometimes in combination with exhaust gas recirculation. Direct injection has been shown to increase power and efficiency, while reducing noxious emissions [4]. Supercharging increases the density of fresh air, thus leading to a higher power output. EGR, the subject of this paper, leads to ${ }_{50}$ improved efficiency and lower emissions [5, 6].

EGR is a way to allow reliable stoichiometric operation at supercharged conditions, without the occurrence of abnormal combustion phenomena. In [5] this resulted in a maximum power output exceeding that of gasoline operation. Due to the thermal capacity of the EGR gases, the emissions of $N O_{x}$, the only 55 hazardous exhaust component of a hydrogen engine, are significantly reduced. Another way to benefit from EGR is by using it to control the engine's power at WOT . This way the pumping losses caused by throttling are avoided, increasing engine efficiency [1]. 
EGR is a promising engine technology for mathrm $\mathrm{H}_{2} \mathrm{ICEs}$, but unlike most other engine parameters, the EGR rate is typically not measured directly, but rather calculated based on other measured data. For meaningful research on the influence of EGR as well as accurate conclusions drawn from such research, the correctness of these calculations are vital. However, most $\mathrm{H}_{2} \mathrm{ICE}$ related research does not specify the way the amount of EGR is calculated, or does it

65 vaguely, with no attention to error analysis. This hinders the analysis of results and comparison between different studies.

In this paper three methods to calculate the amount of EGR in hydrogen fuelled ICEs are developed. For each of these methods a theoretical error analysis is performed, and subsequently evaluated by experimental data. Based on

70 the error analysis a best practice to calculate the EGR\% for mathrm $\mathrm{H}_{2} I C E s$ is proposed.

\section{Methods to determine the EGR rate}

\subsection{Overview of conceivable methods}

The mass fraction of EGR (EGR\%) is defined as the mass flow of EGR divided by the mass flows of EGR, fresh air and fuel:

$$
E G R \%=\frac{\dot{m}_{E G R}}{\dot{m}_{E G R}+\dot{m}_{a i r}+\dot{m}_{H_{2}}}
$$

The mass flows of air and hydrogen can be measured using standard mass flow sensors. However, as the pressure of the chemically aggressive exhaust gases fluctuates, their mass flow is typically not measured directly. In Figure 1 the section where exhaust gases and air are mixed is shown.

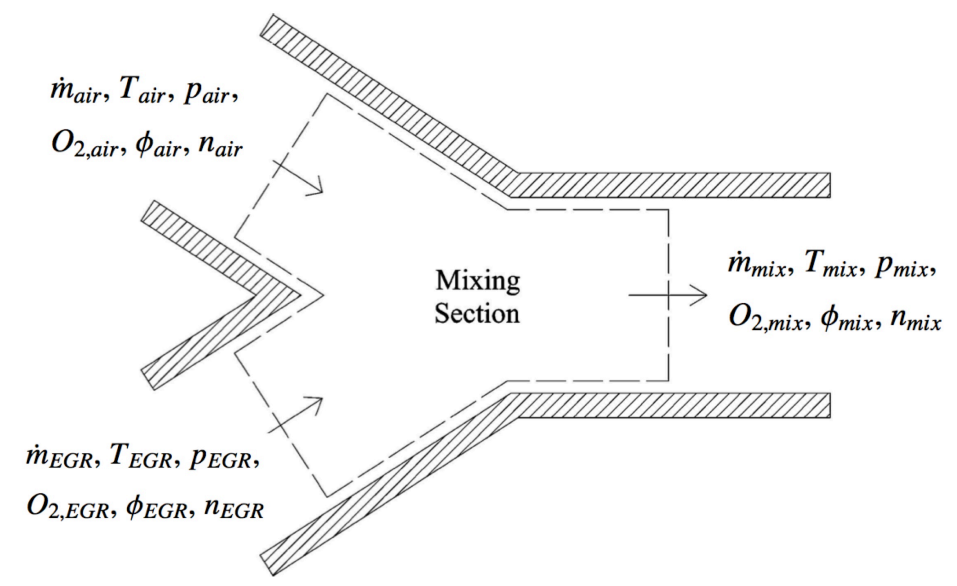

Figure 1: Schematic diagram of the mixing section of exhaust gas and fresh intake air 
The general principle for calculating the EGR rate in hydrocarbon fueled engines is a molar balance of $\mathrm{CO}_{2}$, measured in the intake and exhaust. However, as can be seen in the ideal combustion reaction for $H_{2}$ with air (2), no $\mathrm{CO}_{2}$ is generated.

$$
\begin{cases}\lambda \geq 1: & 2 H_{2}+\lambda\left(O_{2}+3.78 N_{2}\right) \rightarrow 2 H_{2} O+(\lambda-1) O_{2}+3.78 \lambda N_{2} \\ \lambda<1: & 2 H_{2}+\lambda\left(O_{2}+3.78 N_{2}\right) \rightarrow 2 \lambda H_{2} O+2(1-\lambda) H_{2}+3.78 \lambda N_{2}\end{cases}
$$

$\lambda$ is the air-to-fuel equivalence ratio and atmospheric air is assumed to consist ${ }_{85}$ of $79.05 \mathrm{vol} \% \mathrm{~N}_{2}$ and $20.95 \mathrm{vol} \% \mathrm{O}_{2}$.

Therefore, using a molar balance to determine the EGR rate in hydrogen operation will have to be based on other combustion products like $\mathrm{O}_{2}, \mathrm{H}_{2} \mathrm{O}$ and $H_{2}$. The former two are developed in this work. The $H_{2}$ molar balance for EGR determination is not adopted. It requires a non-standard $H_{2}$ concentration

90 sensor and for lean mixtures the amount of $H_{2}$ in the exhaust gases is low compared to other constituents.

Another way to calculate the EGR rate is a volumetric balance in the mixing section. Comparing the intake flow for operation with and without EGR can result in the EGR\%, assuming that the volumetric efficiency of the engine

95 remains the same. As this method is relatively easy to implement on a research engine, it will be examined and its principal assumptions will be verified.

An energy balance, assuming an adiabatic mixing section, can be applied as well to determine the amount of EGR [7]. However, this method can only be used when the temperature difference between the fresh air and EGR gases is 100 sufficient, because the parameter that determines the EGR rate is the temperature of the mixture. Since the engine in this study uses an EGR cooler (see Section 5), minimizing the temperature difference between air and EGR, this method will not be described in this article.

Yet another method is based upon an EGR cooler. When the coolant flow rate, inlet and outlet temperatures, as well as the temperature of the exhaust gases are measured, a heat balance can lead to the EGR rate. However, it is not very practical to measure the coolant flow rate in the EGR cooler. Additionally, the coolant shows no big difference in temperature, which leads to unreliable measurements. For these reasons, this method is not discussed here.

\subsection{Method 1: Calculation based on constant volumetric efficiency}

Assuming that the volume of charge entering the cylinder remains constant irrespective of the mixture's temperature and gas properties, two conditions can be compared: one without and one with EGR. In case of stoichiometric operation this means that the desired load is first set by leaning the mixture, 115 then EGR is gradually added until stoichiometry is reached. The volume of EGR entering the cylinder can then be calculated according to Figure 2. As can be seen, the $\mathrm{H}_{2}$ volume in the cylinder remains constant in both conditions. It is assumed that an equal $H_{2}$ flow with and without EGR results in the same power 
output (identical brake thermal efficiency) and gives similar pressure waves in the intake manifold, resulting in a similar volumetric efficiency [8]. As mentioned earlier, however, EGR can slightly increase the brake thermal efficiency. The assumption of constant volumetric efficiency for developing Equation 3 is further discussed in Section 6.

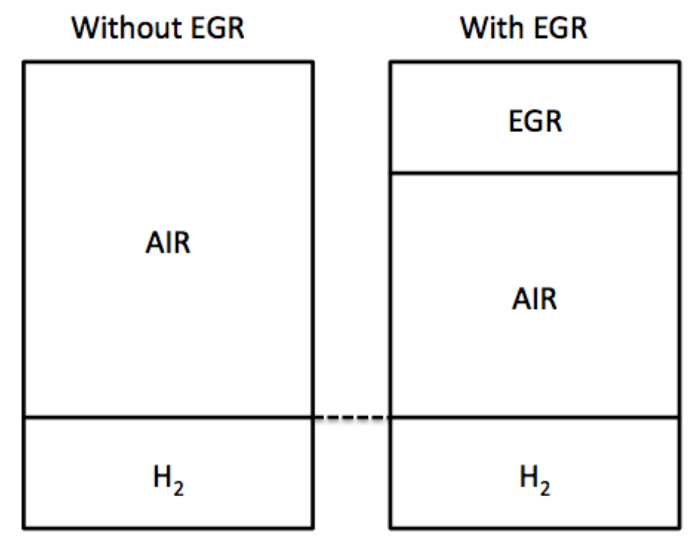

Figure 2: Visualization of the cylinder content with and without use of EGR

This means that the EGR flow rate is equal to the volume of air entering the cylinder without use of EGR minus the volume of air with use of EGR and thus:

$$
\dot{m}_{E G R}=\rho_{E G R} \cdot \Delta Q_{a i r}
$$

with:

$$
\Delta Q_{a i r}=Q_{a i r, 0}-Q_{a i r, 1}
$$

$Q_{\text {air }, 0}$ is the volumetric air flow without EGR and $Q_{\text {air }, 1}$ the volumetric air flow with use of EGR. The volumetric air flow can be measured. The density of the recirculated exhaust gases is calculated through the ideal gas law:

$$
\rho_{E G R}=\frac{p_{E G R}}{R_{E G R} \cdot T_{E G R}}
$$

with $R_{E G R}$ calculated from the combustion reaction (see Appendix B).

To summarize: this method uses sensors to measure $Q_{a i r}, \dot{m}_{H_{2}}, p_{E G R}$ and $T_{E G R}$ and has the advantage of its simplicity. A disadvantage is the requirement to measure two operational conditions in order to apply Equation 4: one without, and one with use of EGR.

2.3. Method 2: Calculation based on the amount of oxygen in the intake and exhaust

Much like the calculation of the EGR rate in conventional hydrocarbon fueled ICEs through a $\mathrm{CO}_{2}$-balance, an oxygen molar balance can be formulated to 
determine the EGR rate in an $\mathrm{H}_{2} \mathrm{ICE}$. This molar balance is defined at the mixing section of the exhaust gases and the intake air, before the hydrogen injection (see Figure 1). The theoretical background of this method is described by Szwaja et al. in [9]. Below, a different derivation to find the EGR rate is described.

145 When the EGR mass rate is written as:

$$
\dot{m}_{E G R}=\dot{n}_{E G R} \cdot M W_{E G R}
$$

With $\dot{n}_{E G R}$ and $M W_{E G R}$ the molar flow rate and molecular weight of the exhaust gases respectively. The molecular weight of the exhaust gases is calculated in Appendix B. To calculate the molar flow rate $\dot{n}_{E G R}$ is written as:

$$
\dot{n}_{E G R}=\frac{y_{E G R, m i x}}{y_{a i r, m i x}} \cdot \dot{n}_{a i r}
$$

With $y_{E G R, m i x}$ and $y_{a i r, m i x}$ the mole fractions of EGR and air in the intake mixture. The air mass flow can be measured, which means that through the molecular weight of air $\left(M W_{\text {air }}\right)$ the air mole rate $\dot{n}_{\text {air }}$ is known. The mole fractions $y_{E G R, m i x}$ and $y_{a i r, m i x}$ can be calculated as a function of the mole fractions of oxygen in air $\left(y_{\mathrm{O}_{2}, \text { air }}\right)$, EGR $\left(y_{\mathrm{O}_{2}, \mathrm{EGR}}\right)$ and intake mixture $\left(y_{\mathrm{O}_{2}, \text { mix }}\right)$. 155 This relation first has to be derived by substituting the following equations:

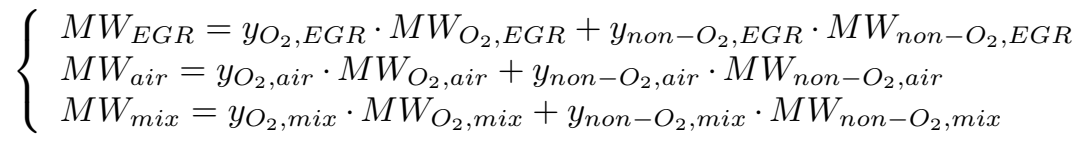

into:

$$
M W_{\text {mix }}=y_{a i r} \cdot M W_{a i r}+y_{E G R} \cdot M W_{E G R}
$$

Which results in:

$$
y_{O_{2}, m i x}=y_{O_{2}, a i r} \cdot y_{a i r, m i x}+y_{O_{2}, E G R} \cdot y_{E G R, m i x}
$$

Where non $-\mathrm{O}_{2}$ stands for all gas components except oxygen.

Substituting $y_{a i r, m i x}=1-y_{E G R, m i x}$ in Equation 10 and solving for $y_{E G R, m i x}$ gives a first expression to substitute in Equation 7. Analogous substitution for $y_{a i r, m i x}$ results in:

$$
\dot{n}_{E G R}=\left(\frac{y_{O_{2}, a i r}-y_{O_{2}, m i x}}{y_{O_{2}, m i x}-y_{O_{2}, E G R}}\right) \cdot \dot{n}_{a i r}
$$

Through Equation 6 we obtain the EGR mass rate:

$$
\dot{m}_{E G R}=\frac{1}{M W_{\text {air }}} \cdot \dot{m}_{a i r} \cdot M W_{E G R} \cdot \Delta y_{O_{2}}
$$


with:

$$
\Delta y_{O_{2}}=\frac{y_{O_{2}, a i r}-y_{O_{2}, m i x}}{y_{O_{2}, m i x}-y_{O_{2}, E G R}} .
$$

The EGR\% is now known by substituting Equation 12 into Equation 1.

165

have to be measured are $\dot{m}_{a i r}, \dot{m}_{H_{2}}, y_{O_{2}, a i r}$ in the intake and $y_{O_{2}, E G R}$ in the exhaust. The first two sensors are normally available on a research engine. They are necessary to determine parameters like $\lambda$. Additionally, an $\mathrm{O}_{2^{-}}$ concentration sensor and the capability to switch between intake and exhaust is lambda sensor. Szwaja et al. used such a sensor in their experiments to measure the oxygen content in the exhaust [9]. This requires a second lambda sensor to measure the $\mathrm{O}_{2}$-concentration in the intake mixture. Using a wide-band lambda sensor induces an additional error to the measured oxygen content due to the 175 conversion of the sensor output voltage to $\mathrm{O}_{2}$ concentration and the influence of $H_{2}$ on the reading [10].

2.4. Method 3: Calculation based on the relative humidity in the intake and exhaust

Instead of determining the EGR rate with an oxygen balance, a calculation

EGR rate is analogous as in 2.3 , however the oxygen concentrations have to be replaced by water concentrations and the subscript ' $n o n-\mathrm{O}_{2}$ ' in Equation 8 by 'dry gases', indicating all of the gases except $\mathrm{H}_{2} \mathrm{O}$.

The EGR mass rate is given by:

$$
\dot{m}_{E G R}=\frac{1}{M W_{\text {air }}} \cdot \dot{m}_{a i r} \cdot M W_{E G R} \cdot \Delta y_{H_{2} O}
$$

185

with:

$$
\Delta y_{H_{2} O}=\frac{y_{H_{2} O, a i r}-y_{H_{2} O, m i x}}{y_{H_{2} O, m i x}-y_{H_{2} O, E G R}} .
$$

Through Equation 1 the EGR\% is now known.

The measurement equipment necessary for this method is summarized below included flow sensors to determine $\dot{m}_{\text {air }}$ and $\dot{m}_{H_{2}}$.

Additionally, to determine the mole fractions of water we can rely on the 190 psychometric principles applied on exhaust gases instead of moist air. Consequently, at each of the three sides of the mixing section (Figure 1) a temperature, pressure and relative humidity sensor are necessary to calculate $y_{\mathrm{H}_{2} \mathrm{O}, \mathrm{EGR}}$;

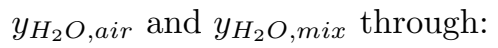

$$
y_{\mathrm{H}_{2} \mathrm{O}}=\frac{\phi \cdot p_{s}}{p}
$$


with $p_{s}$ the saturated water pressure approximated by an equation developed

To find out the best practice to determine the EGR rate, a Taylor accuracy analysis was performed on each method of Section 2. Taylor [12] identified the error of a random function $q=f\left(x_{1}, x_{2}, \ldots, x_{n}\right)$ as:

$$
\delta q=\sqrt{\left(\frac{\partial q}{\partial x_{1}} \cdot \delta x_{1}\right)^{2}+\left(\frac{\partial q}{\partial x_{2}} \cdot \delta x_{2}\right)^{2}+\cdots+\left(\frac{\partial q}{\partial x_{n}} \cdot \delta x_{n}\right)^{2}}
$$

When applying this equation to the $E G R \%$ functions determined by method 1, and 3 in the previous section, three errors $\delta E G R \%$ are obtained. The method that gives the lowest relative error (defined as the ratio $\frac{\delta E G R \%}{E G R \%}$ ), can be selected as the best practice to determine the EGR rate.

\subsection{General accuracy equation of the error made on the EGR\%}

Before studying the accuracy of each method, a general equation describing the relative error on the EGR\% is developed is used in next subsections. This general equation visualizes the parameters having an influence on the dimension of the error.

We start from the definition of the EGR\% (Equation 1):

$$
E G R \%=\frac{\dot{m}_{E G R}}{\dot{m}_{E G R}+\dot{m}_{a i r}+\dot{m}_{H_{2}}}
$$

By applying the Taylor method, we obtain the error on the EGR\% (squared):

$$
\delta E G R \%^{2}=\frac{\left(\dot{m}_{a i r}+\dot{m}_{H_{2}}\right)^{2} \cdot \delta \dot{m}_{E G R}{ }^{2}+\dot{m}_{E G R}^{2} \cdot\left(\delta \dot{m}_{a i r}{ }^{2}+\delta \dot{m}_{H_{2}}{ }^{2}\right)}{\left(\dot{m}_{E G R}+\dot{m}_{a i r}+\dot{m}_{H_{2}}\right)^{4}}
$$

Equation 19 shows that the error on the EGR\% depends on three errors: $\delta \dot{m}_{E G R}, \delta \dot{m}_{a i r}$ and $\delta \dot{m}_{H_{2}}$. The parameters $\dot{m}_{E G R}, \dot{m}_{a i r}$ and $\dot{m}_{H_{2}}$ determine the weight of these errors. As explained in Appendix A.1, this equation can be reshaped into a general equation for the relative error on the EGR\% (Eq. 20) by 
neglecting $\delta \dot{m}_{H_{2}}$ with regard to $\delta \dot{m}_{a i r}, \dot{m}_{H_{2}}$ with regard to $\dot{m}_{a i r}$ and applying the definition of volumetric efficiency $\lambda_{l}$ :

$$
\begin{aligned}
\left(\frac{\delta E G R \%}{E G R \%}\right)^{2}= & \\
& \frac{1}{\left(\lambda_{l} \cdot m_{\text {theor }} \cdot n \cdot \chi\right)^{2}} \cdot\left(\frac{(1-E G R \%)^{2}}{E G R \%^{2}} \cdot \delta \dot{m}_{E G R}{ }^{2}+\delta \dot{m}_{\text {air }}{ }^{2}\right)
\end{aligned}
$$

220 Where $\chi=\frac{1}{2}$ for four-stroke engines and $m_{\text {theor }}$ is the theoretical mass capacity of the cylinder as defined in Appendix A.1. $m_{\text {theor }}$ depends on the actual airfuel ratio $(\lambda)$, the amount of EGR and the cylinder volume. Assuming that $\dot{m}_{E G R}$ and $\dot{m}_{a i r}$ are measured with a measuring device with errors $\delta \dot{m}_{E G R}$ and $\delta \dot{m}_{\text {air }}$, Equation 20 indicates that the relative error on the EGR\% approaches 225 infinity when the EGR\% approaches zero. The relative error reaches a minimum when the $\mathrm{EGR} \%$ is equal to 1, which means that the relative error is a strictly descending function of the EGR\%, and thus the more EGR is used, the better the accuracy of the calculated EGR\%. Furthermore we see in Equation 20 that at constant EGR\% and increasing engine speed or volumetric efficiency $\left(\lambda_{l}\right)$, the relative error on the EGR\% decreases.

As described in Section 1 the EGR mass rate, $\dot{m}_{E G R}$, is typically not measured directly. As a result, the error $\delta \dot{m}_{E G R}$ depends on the accuracy of the devices used to measure the necessary quantities to apply one of the methods described in Section 2. Therefore, an expression for $\delta \dot{m}_{E G R}$ to substitute in Equation 20 will be developed for each method in the following subsections.

\subsection{Accuracy equation of the error on the EGR\% for method 1}

In Section 2.2 we found that the EGR mass rate is equal to:

$$
\dot{m}_{E G R}=\rho_{E G R} \cdot \Delta Q_{a i r}
$$

Applying the Taylor method on this equation, the following equation is obtained after simplification (see Appendix A.2).

$$
\left(\frac{\delta \mathrm{EGR} \%}{E G R \%}\right)^{2}=\frac{1}{\left(\lambda_{l} \cdot m_{\text {theor }} \cdot n \cdot \chi\right)^{2}} \cdot\left(c_{1} \cdot \delta \dot{m}_{\text {air }}^{2}+c_{2} \cdot \delta \dot{m}_{H_{2}}^{2}\right)
$$

With:

$$
\begin{aligned}
& c_{1}=2 \cdot\left(\frac{\rho_{E G R}}{\rho_{\text {air }}}\right)^{2} \cdot \frac{(1-E G R \%)^{2}}{E G R \%{ }^{2}}+1+\frac{2698.77}{\left(1+\frac{0.029}{\lambda}\right)^{4}} \cdot \frac{1}{R_{E G R}^{2}} \cdot \frac{1}{\lambda^{2}} \\
& c_{2}=\frac{2698.77 \cdot L_{s}^{2}}{\left(1+\frac{0.029}{\lambda}\right)^{4}} \cdot \frac{1}{R_{E G R}^{2}}
\end{aligned}
$$

Equation 23 shows us that only $c_{1}$ approaches infinity when the EGR\% approaches zero. 
3.3. Accuracy equation of the error on the EGR\% for method 2

In Section 2.3 we determined the EGR mass rate as:

$$
\dot{m}_{E G R}=\frac{1}{M W_{\text {air }}} \cdot \dot{m}_{a i r} \cdot M W_{E G R} \cdot \Delta y_{O_{2}}
$$

\subsection{Accuracy equation of the error on the EGR\% for method 3}

In Section 2.4 we determined the EGR mass rate as:

$$
\dot{m}_{E G R}=\frac{1}{M W_{a i r}} \cdot \dot{m}_{a i r} \cdot M W_{E G R} \cdot \Delta y_{H_{2} O}
$$

which is similar to $\dot{m}_{E G R}$ of method 2. Consequently, applying Taylor results 255 in a similar equation as in Section 3.3:

$$
\begin{aligned}
\left(\frac{\delta \mathrm{EGR} \%}{E G R \%}\right)^{2}= & \frac{1}{\left(\lambda_{l} \cdot m_{\text {theor }} \cdot n \cdot \chi\right)^{2}} . \\
& \left(c_{1} \cdot \delta \dot{m}_{\text {air }}^{2}+c_{2} \cdot \delta \dot{m}_{H_{2}}^{2}+c_{3} \cdot \delta y_{H_{2} O, a v}{ }^{2}\right)
\end{aligned}
$$


with:

$$
\begin{aligned}
c_{1}= & 2+\frac{2.7 \cdot 10^{-5}}{\left(1+\frac{0.21}{\lambda}\right)^{4}} \cdot \frac{1}{\lambda^{2}} \cdot \frac{1}{M W_{E G R}^{2}} \\
c_{2}= & \frac{2.7 \cdot 10^{-5}}{\left(1+\frac{0.21}{\lambda}\right)^{4}} \cdot \frac{L_{s}^{2}}{M W_{E G R}^{2}} \\
c_{3}= & \frac{\dot{m}_{a i r}^{2}}{\left(y_{H_{2} O, m i x}-y_{H_{2} O, E G R}\right)^{2}} \cdot \\
& \left(2+\frac{2}{x} \cdot \frac{(1-E G R \%)}{E G R \%}+\frac{2}{x^{2}} \cdot \frac{(1-E G R \%)^{2}}{E G R \%^{2}}\right)
\end{aligned}
$$

and $x=\frac{M W_{a i r}}{M W_{E G R}}$. We see that the only difference between Equation 28 and 25 is the error $\delta y_{H_{2} O, a v}$ and the coefficient $c_{3}$.

\section{Experimental Setup}

\subsection{Experimental Equipment}

To evaluate the EGR-calculation methods two series of measurements were gathered on a single cylinder two valve 400cc engine modified to operate on hydrogen fuel. The characteristics of the engine are summarized in Table 1 and the engine's layout is shown in Figure 3. The engine is coupled to a DC motor that can work as generator or motor. A MoTeC M4 Pro ECU is used to control the two Teleflex GFI gas injectors and the ignition timing. The setup is equipped with an exhaust gas recirculation line in which an EGR cooler reduces the temperature of the exhaust gases to $25^{\circ} \mathrm{C}$. The amount of EGR is controlled by varying the duty cycle of a pulse width modulated EGR valve. The mixture of air and exhaust gases is then led to a compressor where the engine intake pressure can be charged up to 2 bar gauge. The intake charge is cooled in an intercooler and sent through a buffer vessel in the combustion chamber. The buffer vessel dampens the air flow in the duct before the vessel to ensure accurate air mass flow measurements.

A first series of measurements focused on the first two methods. The third method was not applied since no humidity sensors were available at the time. Method 2 and 3 were separately analysed in a second set of experiments. Each method requires several sensors, which have their influence on the accuracy of the EGR calculation. In Table 2 the sensors that are used for the experimental validation of the methods are listed with their respective accuracies. For method 2, the $\mathrm{O}_{2}$ concentration can be measured using a wide band $\lambda$ sensor (method 2(a)) or an exhaust gas analyser (method 2(b)). For method 3, the humidity of the intake air is assumed to be the same as the atmospheric humidity. A stationary sensor is installed in the lab to measure atmospheric conditions including the humidity. The relative humidity of EGR gas is assumed to be $100 \%$ as water vapor condensed in the EGR cooler. For the mixed intake gas, 


\begin{tabular}{|l|c|}
\hline Cylinders & 1 \\
Valves & 2 \\
Bore/stroke (mm) & $77.5 / 86.4$ \\
Displacement (cc) & 407.3 \\
Compression ratio & $10.17: 1$ \\
IVO & $7^{\circ} \mathrm{CA} \mathrm{BTDC}$ \\
IVC & $66^{\circ} \mathrm{CA} \mathrm{ABDC}$ \\
EVO & $64^{\circ} \mathrm{CA}$ BBDC \\
EVC & $21^{\circ} \mathrm{CA}$ ATDC \\
Injection & PFI \\
\hline
\end{tabular}

Table 1: Engine characteristics

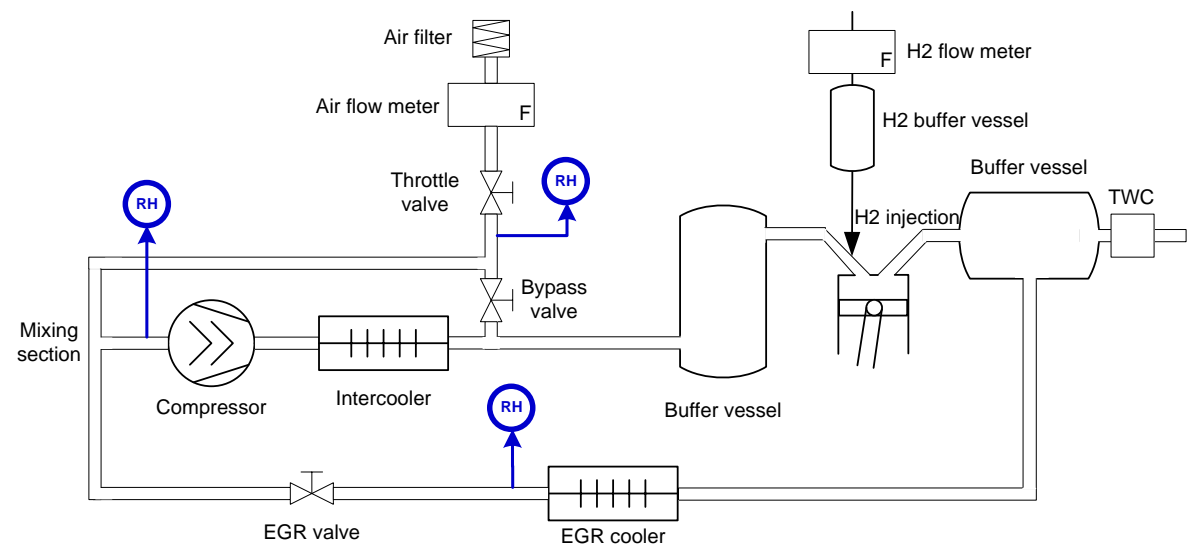

Figure 3: Test engine layout with indicated measuring places for relative humidity $(\mathrm{RH})$

the relative humidity is measured using a capacitive humidity sensor (Honeywell HIH-4000).

\subsection{Experimental Procedure}

290

The first set of experiments was taken at different conditions for load, engine speed and EGR rate. The engine speed was varied between 1800 and 3000 rpm, no supercharging was applied and $\lambda$ was set close to 1 to ensure high conversion efficiencies of the three-way catalyst. Recorded quantities included torque, engine speed, air and hydrogen mass flow, oxygen concentration in intake and exhaust, intake and exhaust pressure and pollutant emissions. The dataset covers a wide range of EGR\% in order to investigate the applicability of the methods for low and high EGR rates.

The second set of experiments was also obtained in normally aspirated conditions, but $\lambda$ was not kept constant. Engine speed was varied between 1500 and $2000 \mathrm{rpm}$ and three different $H_{2}$ flow rates were considered $(2.8,3.2$ and 3.7 


\begin{tabular}{|c|c|c|}
\hline Device & Variable & Accuracy \\
\hline Bronkhorst Hi-tec F-106BZ-HD-01-V & air flow & $\delta_{Q_{\text {air }}}=0.6 \mathrm{~m}^{3} / \mathrm{h}$ \\
Bronkhorst Hi-tec F-113AC-HDD-55V & $H_{2}$ flow & $\delta_{Q_{H_{2}}}=0.18 \mathrm{~m}^{3} / \mathrm{h}$ \\
Sick Maihak & $O_{2}$-concentration & $\delta_{O_{2}}=0.25 \mathrm{vol} \%$ \\
Honeywell HIH-4000 & relative humidity & $\delta \phi=3.5 \%$ \\
ATAL TRP232-102D & atmospheric rel. hum. & $\delta \phi=2.5 \%$ \\
\hline
\end{tabular}

Table 2: Measuring equipment for EGR analysis

$\mathrm{Nm}^{3} / \mathrm{hr}$ ). Torque was not controlled and depended on the EGR rate, which was varied between lower and upper bounds restricted by back-fire and combustion stability respectively. The EGR and mixture temperatures were not controlled, but depended on the operating conditions, since the coolant flow rate through the EGR cooler was kept constant. This resulted in a wide range of conditions to compare the different methods. The experimental conditions for both datasets are summarized in Appendix E.

\section{Results and Discussion}

\subsection{Theoretical discussion of the accuracy equations}

To compare the accuracy of all three methods, variables such as $\lambda$ and the oxygen content in the mixture $\left(O_{2, m i x}\right)$ have to be substituted in the coefficients $c_{1}, c_{2}$ and $c_{3}$. In this section, we will simulate realistic values for these variables in order to evaluate these coefficients. Variables that are common for each method are the air-fuel ratio $(\lambda)$, the amount of EGR (EGR\%), the engine speed, the volumetric efficiency and the theoretical mass entering the cylinder $\left(m_{\text {theor }}\right)$.

$\lambda$ is set to 1 for the simplicity of substituting this value in the coefficients $c_{1}, c_{2}$ and $c_{3}$. This value does not differ significantly with $\lambda$ in the first set of experiments. Choosing stoichiometric conditions implies that:

$$
\begin{aligned}
M W_{E G R} & =0.0245 \frac{\mathrm{kg}}{\mathrm{mol}} \\
R_{E G R} & =338.8 \frac{\mathrm{J}}{\mathrm{kg} \mathrm{K}}
\end{aligned}
$$

Where both $M W_{E G R}$ and $R_{E G R}$ are calculated as detailed in Appendix B. The relative error increases with decreasing EGR\% and engine speed, as decribed in the previous section. This means that when we want to compare the relative errors of all methods, one of those variables has to remain constant while the other varies. We keep the engine speed constant at $2500 \mathrm{rpm}$ and vary the amount of EGR from $10 \%$ to $50 \%$. Because $m_{\text {theor }}$ depends on $\lambda$ and the amount of EGR, this variable is now known at every EGR\%. The volumetric efficiency $\lambda_{l}$ is estimated to be $85 \%$ irrespective of the EGR\%. 
The errors of the measurement devices are another important set of variables. To allow a comparison between the results of this subsection with the

experimental results, we use the same errors as in Section 5.2, except for $y_{\mathrm{H}_{2} \mathrm{O}, \mathrm{av}}$ :

$$
\begin{aligned}
\delta \dot{m}_{a i r} & =0.775 \frac{\mathrm{kg}}{\mathrm{h}} \\
\delta \dot{m}_{\mathrm{H}_{2}} & =0.0162 \frac{\mathrm{kg}}{\mathrm{h}} \\
\delta y_{\mathrm{O}_{2}} & =0.25 \% \\
\delta y_{\mathrm{H}_{2} \mathrm{O}, a v} & =0.005 \%
\end{aligned}
$$

The variables that are inherent to the method are determined as follows:

- Method 1: the coefficients $c_{1}$ and $c_{2}$ (equation 23) depend on the amount of EGR, $\lambda, R_{E G R}, \rho_{\text {air }}$ and $\rho_{E G R}$. The values of the first three variables are set as described above. The last two are determined by the ideal gas law and consequently, they depend on the pressure and temperature. If we assume that $T_{E G R}=T_{a i r}$ and $p_{E G R}=p_{a i r}$, the ratio $\frac{\rho_{E G R}}{\rho_{a i r}}$ (to be substituted in $c_{1}$ ) is equal to:

$$
\frac{\rho_{E G R}}{\rho_{\text {air }}}=\frac{R_{\text {air }}}{R_{E G R}}=\frac{286.9 \frac{\mathrm{J}}{\mathrm{kg} \cdot \mathrm{K}}}{338.8 \frac{\mathrm{J}}{\mathrm{kg} \cdot \mathrm{K}}}=0.85
$$

- Method 2: besides the common variables described above, the coefficients $c_{1}, c_{2}$ and $c_{3}$ depend on $\dot{m}_{a i r}, y_{O_{2}, m i x}$ and $y_{O_{2}, E G R}$. The mass air flow is determined as the product of the volumetric efficiency with the theoretical mass air flow. According to the combustion reaction (Equation 2) there is no oxygen in the exhaust gases when working stoichiometrically, which means $y_{O_{2}, E G R}=0 \%$. The oxygen content in the mixture is calculated as a function of the amount of EGR. Reasoning that $y_{O_{2}, m i x}$ should be equal to $y_{\mathrm{O}_{2}, \text { air }}(=20.95 \%)$ when the $E G R \%=0 \%$ and equal to $y_{O_{2}, E G R}$ $(=0 \%)$ when the $E G R \%=100 \%$, and assuming a linear function between both values, we get:

$$
y_{\mathrm{O}_{2}, m i x}=\left(y_{\mathrm{O}_{2}, E G R}-y_{\mathrm{O}_{2}, a i r}\right) \cdot E G R \%+y_{\mathrm{O}_{2}, a i r}
$$

- Method 3: the only difference in variables between method 2 and method 3 is that instead of the oxygen content in the mixture and exhaust gases, the water content $\left(y_{\mathrm{H}_{2} \mathrm{O}, \mathrm{mix}}\right.$ and $\left.y_{\mathrm{H}_{2} \mathrm{O}, \mathrm{EGR}}\right)$ has to be determined. To determine $y_{H_{2} O, E G R}$ (Equation A.13), we assume $p_{E G R}=90000 \mathrm{~Pa}$ and that $p_{s}$ is calculated (through Wexler's equation) with $T_{E G R}=25^{\circ} \mathrm{C}$. Because of the great amount of $\mathrm{H}_{2} \mathrm{O}$ in the exhaust gases it is very likely that condensation occurs. Therefore, we assume $\phi=100 \%$ which means $y_{H_{2} O, E G R}=3.52 \%$. The amount of water vapor in the mixture, $y_{H_{2} O, m i x}$, 
is determined at $p_{m i x}=90000 \mathrm{~Pa}, T_{m i x}=24^{\circ} \mathrm{C}$ and with $\phi_{m i x}$-similar to $y_{O_{2}, m i x^{-}}$determined as a function of the amount of EGR:

$$
\phi_{m i x}=\left(\phi_{E G R}-\phi_{a i r}\right) \cdot E G R \%+\phi_{a i r}
$$

With this simulated dataset, we obtain that the relative error on the EGR\% for all three methods varies as a function of the EGR\% according to Figure 4. This 360 Figure is analyzed and discussed in Section 6.

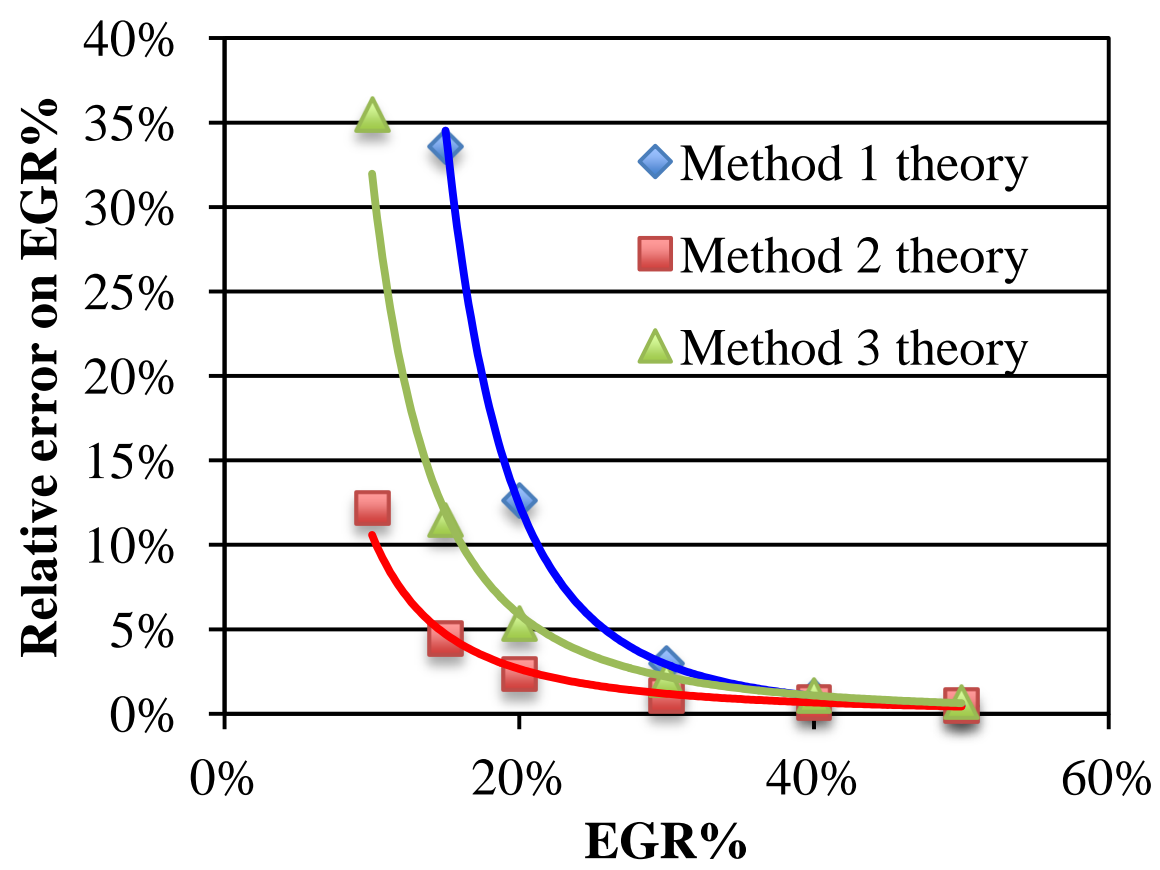

Figure 4: Relative error on the EGR\% vs EGR\%. Markers: calculation results. Lines: best fits

\subsection{Experimental discussion of the accuracy equations}

\subsubsection{Calculated EGR\% for the different methods}

In Figure 5 the calculated EGR ratios are compared for method 1 and 2, and for method 2 and 3 using the first and second experimental dataset respectively.

For the second dataset the $\mathrm{O}_{2}$ concentration was separately measured using both a $\lambda$ sensor and an exhaust gas analyzer. 


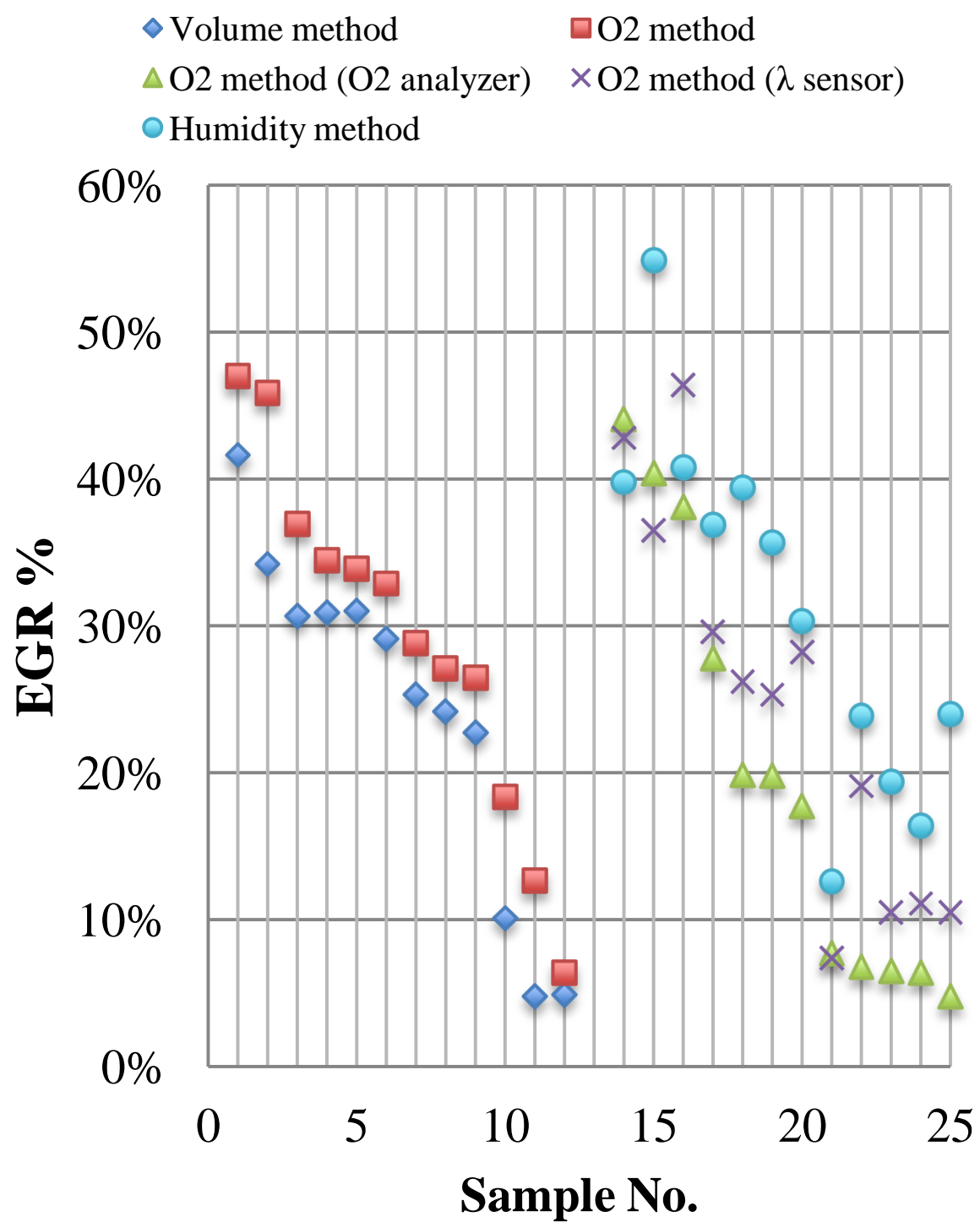

Figure 5: Comparison of the calculated EGR\% using different methods. Experimental dataset 1: sample 1-12. Experimental dataset 2: sample 14-25

The EGR\% for the first and second method is calculated and visualized for the twelve samples of the first dataset in Figure 5. Both methods follow the same trend, but the second method gives a slightly higher value than the first. 370 This difference originates from the equation of the EGR mass rate as calculated in Section 2. In Appendix D the ratio of equation 3 and 12 is calculated and 
it is concluded that the offset between both methods depends on the operating parameters of the considered measurement condition.

The results for the second dataset show that method 2(a) and 2(b) produce a similar trend, but compared to method 2(a), method 2(b) gives EGR\% that are slightly higher for low EGR ratios and slightly lower for high EGR ratios. This is possibly due to the calibration of the $\lambda$ sensor, which is insufficiently adapted to the very lean mixtures employed in hydrogen operation [10]. Method 3 results in higher values for EGR\% at almost all measurement conditions.

\subsubsection{The relative error on the EGR\%}

In Figures 6 and 7 the relative error on the EGR\% calculated using the following methods is compared:

- Volume method (Method 1), with experimental dataset 1

- $\mathrm{O}_{2}$ method (Method 2), with experimental dataset 1

- $\mathrm{O}_{2}$ method using $\mathrm{O}_{2}$ analyzer (Method 2(a)), with experimental dataset 2

- $O_{2}$ method using $\lambda$ sensor (Method 2(b)), with experimental dataset 2

- Method 3, with experimental dataset 2

For method 3, a case study is performed in which the absolute error of the 390

relative humidity sensors was varied between $1.5 \%$ and $3.5 \%$. The upper bound represents the accuracy as reported by the manufacturer. The lower bound is the minimum achievable error after additional calibration in a climate room with a known humidity. 
$\checkmark \quad$ Volume method

$\Delta \quad \mathrm{O} 2$ method (O2 analyzer)

Humidity method

- - - - Power (O2 method)
- O2 method

$\times \quad$ O2 method ( $\lambda$ sensor)

Power (Volume method)

Power (Humidity method)

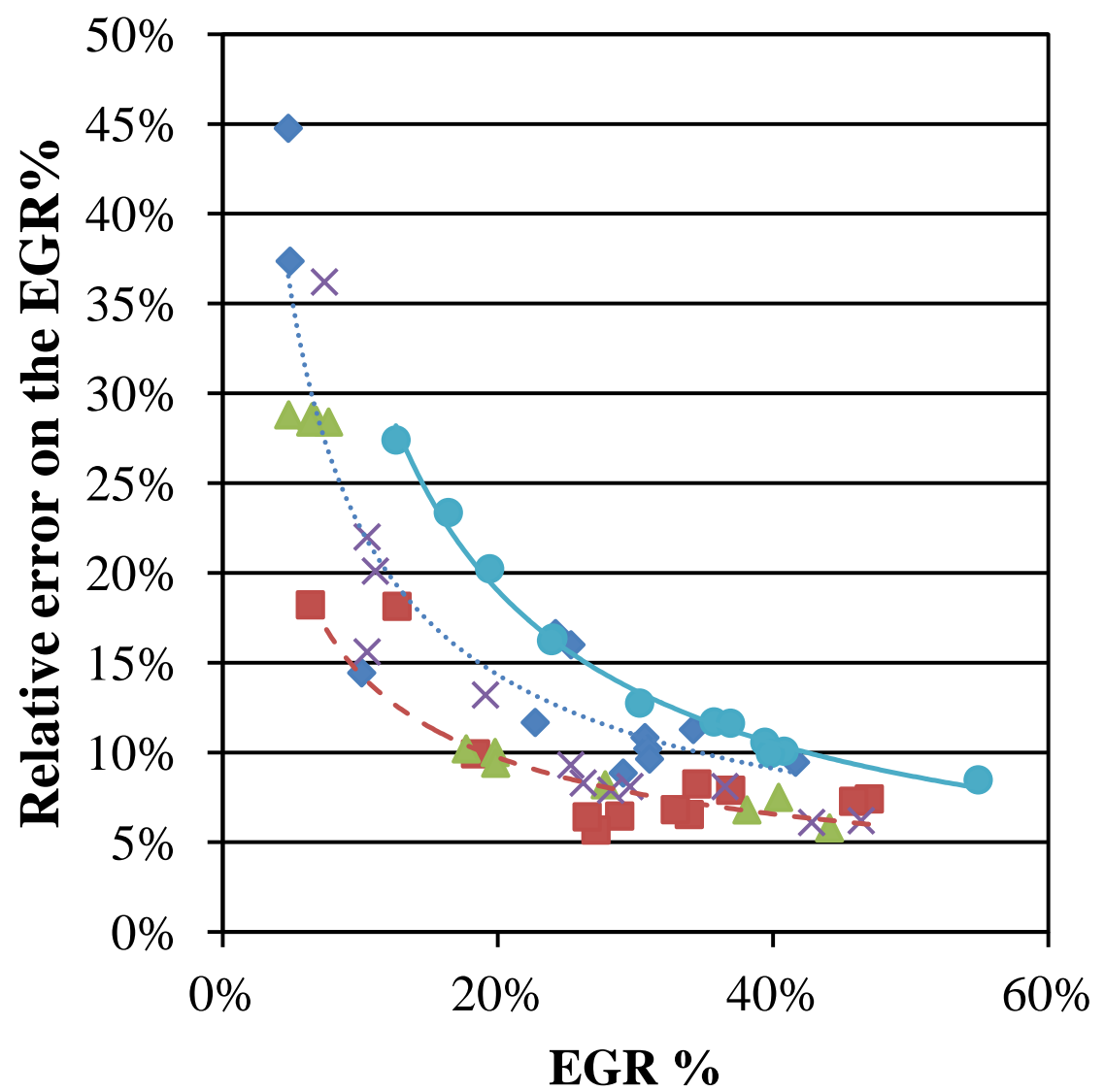

Figure 6: Comparison of the relative error on EGR\% calculated using three different methods. Method 1 and 2 - dataset 1. Method 2(a), 2(b) and 3 - dataset 2. Error on the relative humidity $\delta \phi=1.5 \%$ 


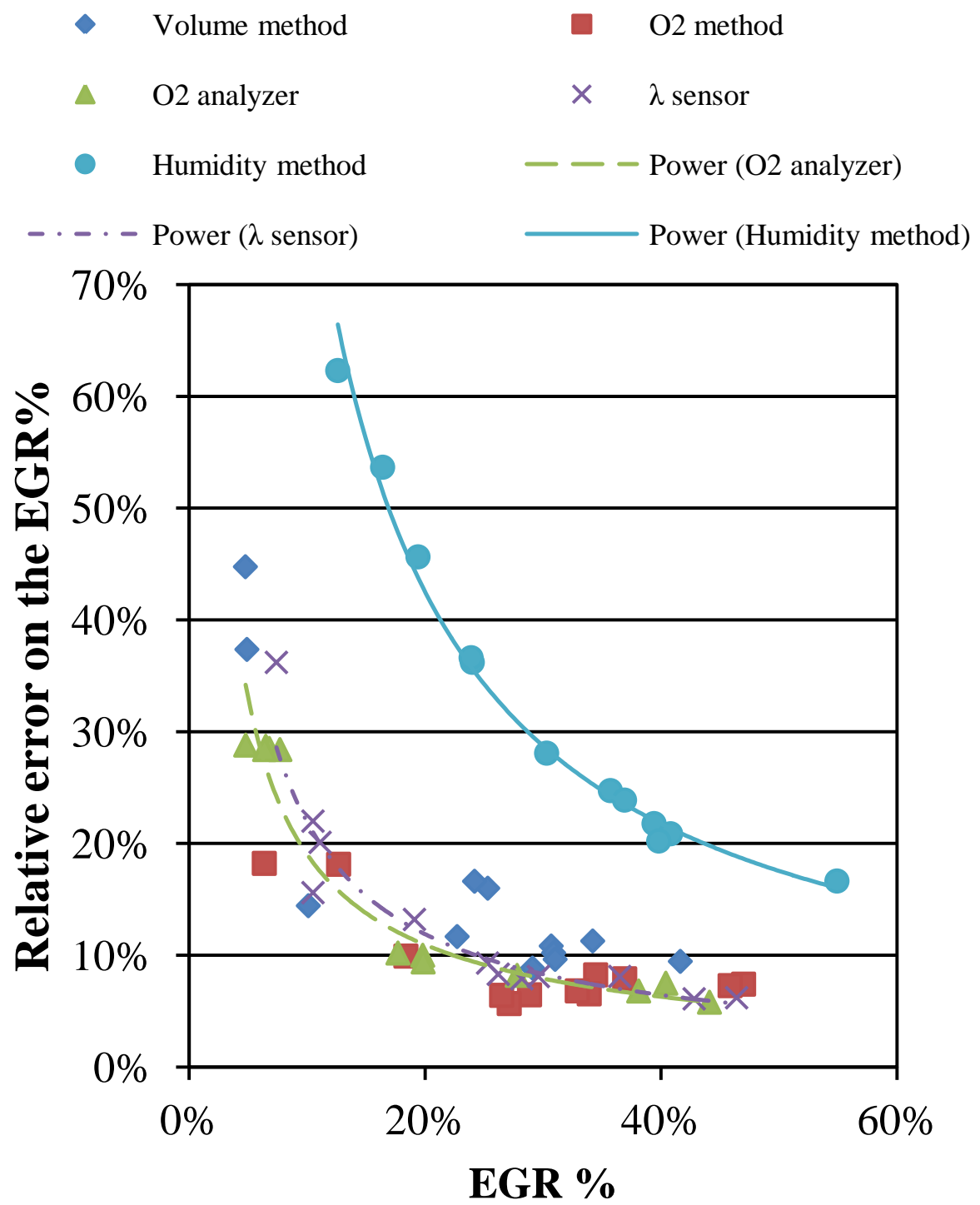

Figure 7: Comparison of the relative error on EGR\% calculated using three different methods. Method 1 and 2 - dataset 1. Method 2(a), 2(b) and 3 - dataset 2. Error on the relative humidity $\delta \phi=3.5 \%$

The significant measurement errors for the first method are $\delta Q_{\text {air }}$ and $\delta Q_{H_{2}}$ 395 and for the second method $\delta y_{O_{2}}, \delta Q_{a i r}$ and $\delta Q_{H_{2}}$. With the values defined in Table 2, the relative error on the EGR\% is calculated for all twelve samples of the first dataset and given as a function of the EGR\% in Figure 6, where a trend 
line is added. We see that all methods follow the same trend, a rising relative error for decreasing EGR\%. Additionally, we see that the relative error for the second method is markedly smaller than that for the first method.

The errors for method 2(a) and 2(b), calculated based on dataset 2, and method 2, calculated based on dataset 1 , are very similar. The relative errors for method 2 and dataset 1 are slightly lower, as the first dataset was obtained in stoichiometric conditions and the second dataset in lean conditions. As can

405 be seen from Equation 26 lean conditions lead to larger values for $c_{1}, c_{2}$ and $c_{3}$ and thus a larger relative error. Method 3 produces the largest errors. Even in the case of a carefully calibrated sensor $(\delta \phi=1.5 \%)$ the error is still higher than for the other methods.

\section{Discussion}

The relative error on the EGR\%, obtained with the experiments in Figure 6, can be compared to the theoretically obtained relative error in Figure 4 for all methods. We observe that the error rises exponentially with decreasing EGR\% for both figures. Considering the relative position of the error for the first two methods, the same conclusion can be drawn from theory and experimental data. Over the entire EGR\%-range the second method is more accurate than the first method, especially for EGR\% lower than 20\%. The third method, however, leads to EGR\% errors that are significantly larger than the theoretical curve in Figure 4 . This is a results of the very small value for the error on the water vapor concentration $\left(\delta y_{\mathrm{H}_{2} \mathrm{O}}=0.005 \%\right)$ that was applied in the theoretical calculation.

${ }_{420}$ This would correspond to an error in the relative humidity of less than $0.5 \%$, whereas a realistic lower limit for this error is $1.5 \%$. Even with the minimal achievable error of $1.5 \%$, the error associated with method 3 is well above that of the other two methods.

The trendlines in Figure 6 and lines in Figure 4 do not match completely. ${ }_{425}$ The experimental trendline of the relative error is shifted towards lower EGR\% compared to the theoretically obtained line. This can be ascribed to the large variation in engine speed and $\lambda$ in the dataset, which has a large influence on the EGR\% (see Section 3). A better match could likely be obtained if each sample was taken at the same engine speed and volumetric efficiency.

${ }_{430}$ If a proposed method is adopted, it is necessary to know which measurement device has the largest influence on the error. For each method, the equation of the relative error has only one measurement error with a coefficient depending on the EGR\%. As can be seen in Figure 6 and 4 this measurement error will have the biggest influence for low amounts of EGR. The influence of the other ${ }_{435}$ measurement devices can be visualized by taking the EGR\% limit of $100 \%$, because then the measurement error depending on the EGR\% has no influence on the error. These are very small for all three methods. In conclusion we can state that for the first method the accuracy of the air mass flow, for the second method of the $\mathrm{O}_{2}$-concentration and for the third method of the relative 
The discussion above only takes the influence of measurement errors into account. The calculated EGR\% will also differ from the actual value due to assumptions made in the theoretical setup of the methods. The difference of EGR\% between the first and second method in Figure 5 is a result of such an assumption.

For the first method the influence of the primary assumptions was investigated experimentally. In Section 2.2 a constant volumetric efficiency is presumed, irrespective of changes in intake temperature or gas properties. However, increasing the amount of exhaust gases in the intake charge, will rise its temper450 ature and result in a reduced volumetric efficiency (defined based on the mass flow of fresh air and EGR into the cylinder). Tests were conducted on a directinjection 500cc SI engine to investigate the influence of that assumption by measuring the air flow into the cylinder at various intake temperatures (Figure 8). It can be observed that there is a correlation between the intake temperature and the mass and volume flow of air into the engine cylinder. Through this correlation a scaling factor is derived and applied to the equation of the EGR\% to neutralize the effect of varying temperature. This results in an increase in EGR $\%$ of approximately $2 \%$. 


\section{- Avg. Temp [deg C] $\quad \Delta$ Volume air flow $\left[\mathrm{m}^{3} / \mathrm{h}\right]$}

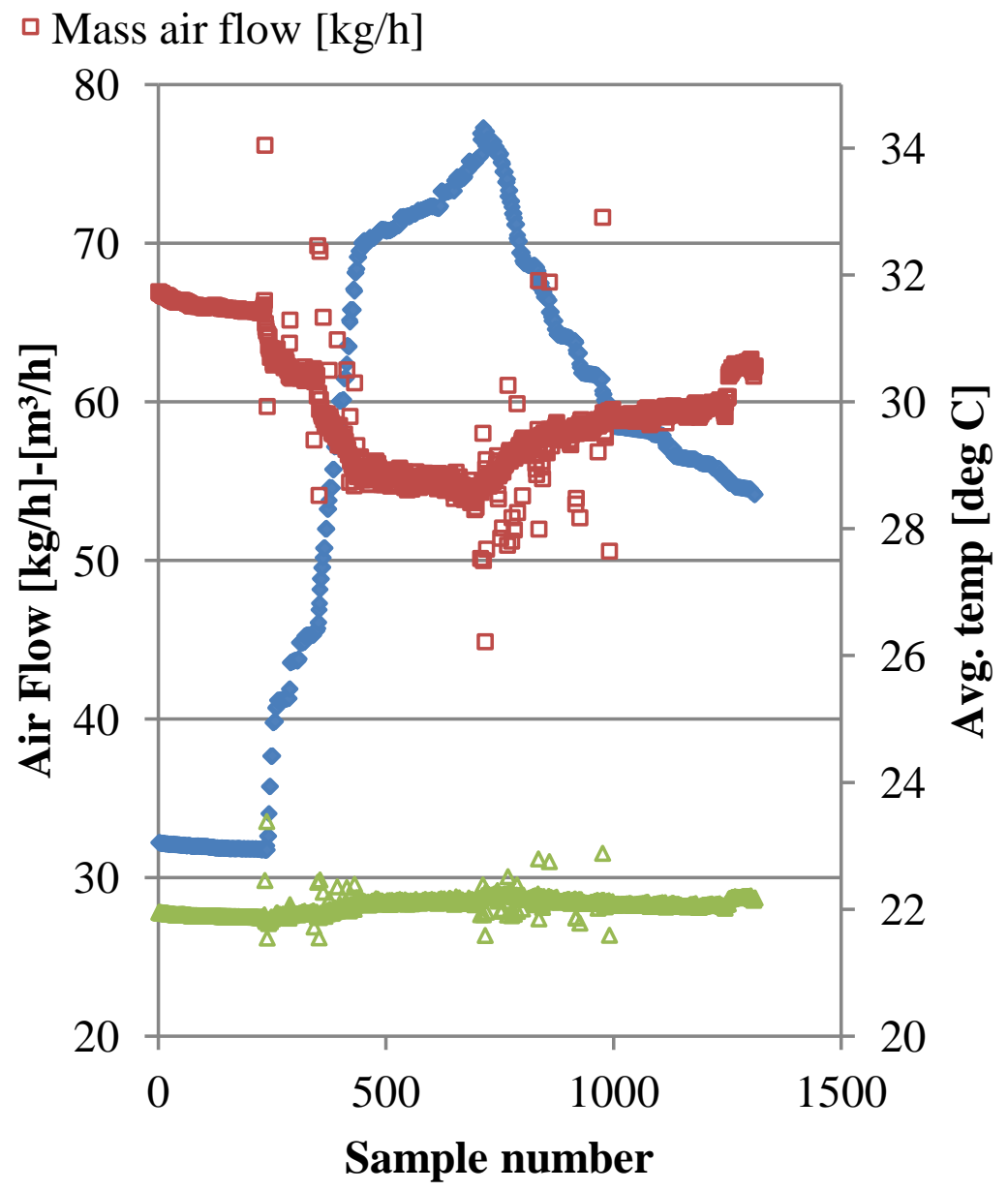

Figure 8: Investigation of the correlation between intake temperature and intake air volume on a direct-injection 500 cc single cylinder SI engine

In the experimental results of Section 5, however, this has only a minor influence due to the use of an EGR cooler. It reduces the exhaust gas temperature to $25^{\circ} \mathrm{C}$, which is only slightly higher than the air temperature of $22^{\circ} \mathrm{C}$.

The third method is based on a relative humidity measurement. Relative humidity sensors are calibrated in a climate chamber with a controlled humidity. However, exhaust gas has a different composition than the gas used for the calibration. This will affect the accuracy of the measurement depending on the exact gas composition and thus on different factors such as air-fuel ratio, engine load, EGR\%, etc. Measuring the relative humidity in exhaust gas with a 
conventional relative humidity sensor adds an additional source for error on the calculated EGR\% besides the measurement error, further limiting the practical use of method 3 .

Unlike the first and third method, for the second method, there are no principal assumptions that could significantly influence the calculated EGR\% in the theoretical development of the equation of the EGR rate.

\section{Conclusions}

Three methods to determine the amount of EGR in a hydrogen ICE have been developed and tested for their accuracy by means of an error analysis. The first method is based upon a volume balance in the mixing section of exhaust gases and fresh air. The second and third method use a molar balance of $\mathrm{O}_{2}$ and $\mathrm{H}_{2} \mathrm{O}$ respectively. Engine measurements were performed to validate the theoretical analysis.

For all methods, the relative error on the calculated EGR\% rises exponentially with decreasing EGR\%. Overall, the second method, based on a molar balance of $\mathrm{O}_{2}$, results in the lowest relative errors. The third method seems least practical, as the relative humidity sensors used in this method do not have the required accuracy to ensure an acceptable error on the calculated EGR\%.

In addition to the error analysis, the assumptions to develop the theoretical equations and the feasibility of a method should be considered as well. The first method is easy to implement in an engine, but assumes a constant volumetric efficiency. This assumption was shown to be incorrect, as the change in inlet 490 temperature caused by the hot EGR gases can change the volumetric efficiency and should be corrected for. The equation for the EGR rate of the second method is developed without any assumptions. To apply this method only one extra oxygen sensor is needed. This can be an $O_{2}$ gas analyzer, for stationary applications, or a wide band lambda sensor, for production engines. The third method needs relative humidity sensors, which are usually not present on an engine. Furthermore, this method assumes that a humidity measurement can be applied to exhaust gases, whereas such a sensor is generally calibrated in a humidity chamber with moist air.

Taking into account the assumptions of each method, the error analysis performed on the amount of EGR and the relative simplicity of implementation, the method based on an oxygen molar balance is concluded to be the best practice for determining the EGR rate in hydrogen engines.

\section{Acknowledgements}

J. Vancoillie acknowledges a Ph. D. fellowship (FWO09/ASP/030) of the 505 Research Foundation - Flanders (FWO). The Research Foundation - Flanders has also funded the experimental equipment (1.5.147.10N). The authors would like to thank Interreg IV for its support through the project HYDROGEN REGION Flanders - South Netherlands. 
Parts of the submitted manuscript have been created by UChicago Argonne, LLC, Operator of Argonne National Laboratory ('Argonne'). Argonne, a U.S. Department of Energy Office of Science laboratory, is operated under Contract No. DE-AC02-06CH11357. The U.S. Government retains for itself, and others acting on its behalf, a paid-up nonexclusive, irrevocable worldwide license in said article to reproduce, prepare derivative works, distribute copies to the public, 515 and perform publicly and display publicly, by or on behalf of the Government.

Part of the research referenced in this manuscript was funded by DOE's FreedomCAR and Vehicle Technologies Program, Office of Energy Efficiency and Renewable Energy. T. Wallner wishes to thank Gurpreet Singh and Lee Slezak, program managers at DOE, for their support. A hydrogen engine used 520 to run certain experiments presented in this manuscript was provided by Ford Motor Company. Special thanks to the team from Ford Motor Company for their support. 


\section{Bibliography}

[1] Verhelst S, Wallner T. Hydrogen-fueled internal combustion engines. Prog Energ Combust 2009;35(6):490-527.

[2] Abbott D. Keeping the energy debate clean: How do we supply the world's energy needs? Proc IEEE 2010;98(1):42-66.

[3] Das LM. Hydrogen engines: A view of the past and a look into the future. Int J Hydrogen Energ 1990;15(6):425-43.

[4] Matthias NS, Wallner T, Scarcelli R. A hydrogen direct injection engine concept that exceeds U.S. DOE light-duty efficiency targets. SAE International; 2012. SAE paper no. 2012-01-0653.

[5] Verhelst S, Maesschalck P, Rombaut N, Sierens R. Increasing the power output of hydrogen internal combustion engines by means of supercharging and exhaust gas recirculation. Int J Hydrogen Energ 2009;34(10):4406-12.

[6] Wallner T, Nande AM, Scarcelli R. Evaluation of exhaust gas recirculation (EGR) in combination with direct injection (DI) on a hydrogen research engine. In: 3rd World Hydrogen Technology Convention. Delhi, India; 2009, p. 1-6.

[7] Beck NJ, Wong HC, Gebert K. Clean air power inc., assignee. EGR control system and method for an internal combustion engine. United States Patent US 6,742,335; 2004 July 11.

[8] Heffel JW. NOx emission reduction in a hydrogen fueled internal combustion engine at $3000 \mathrm{rpm}$ using exhaust gas recirculation. Int J Hydrogen Energ 2003;28(11):1285-92.

[9] Szwaja S, Naber JD. Exhaust gas recirculation strategy in the hydrogen SI engine. In: Journal of KONES 2007: Powertrain and Transport; vol. 14. Warsaw, Poland; 2007, p. 1-8.

[10] Verhelst S, Sierens R. Hydrogen engine-specific properties. Int J Hydrogen Energ 2001;26(9):987-90.

[11] Alduchov OA, Eskridge RE. Improved magnus form approximation of saturation vapor pressure. J Appl Meteorol 1996;35(4):601-9.

[12] Taylor JR. An introduction to Error Analysis. Sausalito, CA: University Science Books; 2nd ed.; 1997. 


\section{Appendix A. Accuracy calculation of the methods to determine the} EGR rate

Appendix A.1. General accuracy equation of the error made on the EGR\%

We start from the definition of the EGR\% (equation 1):

$$
E G R \%=\frac{\dot{m}_{E G R}}{\dot{m}_{E G R}+\dot{m}_{a i r}+\dot{m}_{H_{2}}}
$$

By applying Taylor, we obtain the error on the EGR\% (squared):

$$
\delta E G R \%^{2}=\frac{\left(\dot{m}_{a i r}+\dot{m}_{H_{2}}\right)^{2} \cdot \delta \dot{m}_{E G R}{ }^{2}+\dot{m}_{E G R}^{2} \cdot\left(\delta \dot{m}_{a i r}{ }^{2}+\delta \dot{m}_{H_{2}}{ }^{2}\right)}{\left(\dot{m}_{E G R}+\dot{m}_{a i r}+\dot{m}_{H_{2}}\right)^{4}}
$$

Equation 19 shows that the error on the EGR\% depends on three errors: $\delta \dot{m}_{E G R}, \delta \dot{m}_{a i r}$ and $\delta \dot{m}_{H_{2}}$. The parameters $\dot{m}_{E G R}, \dot{m}_{a i r}$ and $\dot{m}_{H_{2}}$ determine the weight of these errors.

To simplify this equation two assumptions are made:

1. $\dot{m}_{H_{2}}$ is neglected with regard to $\dot{m}_{\text {air }}$. To justify this, we extract the ratio of $\dot{m}_{H_{2}}$ and $\dot{m}_{\text {air }}$ out of the equation for $\lambda$ :

$$
\lambda=\frac{L_{w}}{L_{s}}=\frac{1}{L_{s}} \cdot \frac{\dot{m}_{a i r}}{\dot{m}_{H_{2}}} \Rightarrow \frac{\dot{m}_{H_{2}}}{\dot{m}_{\text {air }}}=\frac{1}{34.2 \cdot \lambda}
$$

with $L_{s}$ the stoichiometric AFR for hydrogen combustion in air as 34.2:1. We conclude that the assumption can be made, as $\dot{m}_{H_{2}}$, for $\lambda=1$, only amounts to $3 \%$ of $\dot{m}_{\text {air }}$.

2. $\delta \dot{m}_{H_{2}}^{2}$ is neglected with regard to $\delta \dot{m}_{a i r}^{2}$. Applying Taylor on the ratio of $\dot{m}_{H 2}$ and $\dot{m}_{a i r}$ with $\dot{m}_{H_{2}}=\rho_{H_{2}} \cdot Q_{H_{2}}$ and $\dot{m}_{a i r}=\rho_{a i r} \cdot Q_{a i r}$ gives:

$$
\frac{\delta \dot{m}_{H_{2}}^{2}}{\delta \dot{m}_{\text {air }}^{2}}=\frac{\left(\rho_{H_{2}} \cdot \delta_{Q H_{2}}\right)^{2}}{\left(\rho_{\text {air }} \cdot \delta Q_{\text {air }}\right)^{2}}=0.005 \cdot \frac{\delta Q_{H_{2}}{ }^{2}}{\delta Q_{\text {air }}{ }^{2}}
$$

This means that if the errors $\delta Q_{H_{2}}$ and $\delta Q_{\text {air }}$ have a similar dimension, equation A.2 justifies the second assumption. In case a device is utilized that measures $\dot{m}_{a i r}$ and $\dot{m}_{H_{2}}$ directly, this assumption is justified because normally the ratio of the errors $\delta \dot{m}_{H_{2}}$ and $\delta \dot{m}_{a i r}$ is similar to the ratio of equation A.1.

With these assumptions equation 19 is simplified to:

$$
\left.\delta E G R \%^{2}=\frac{\dot{m}_{a i r}^{2}}{\left(\dot{m}_{E G R}+\dot{m}_{a i r}\right)^{4}} \cdot \delta \dot{m}_{E G R}^{2}+\frac{\dot{m}_{E G R}^{2}}{\left(\dot{m}_{E G R}+\dot{m}_{a i r}\right)^{4}} \cdot \delta \dot{m}_{a i r}{ }^{2} \mathrm{~A} .3\right)
$$


To further simplify this equation four substitutions can be made. When we neglect $\dot{m}_{H_{2}}$ with regard to $\dot{m}_{a i r}$ in equation 18 , we can derive the first three equations to substitute:

$$
\begin{aligned}
\frac{\dot{m}_{E G R}^{2}}{\left(\dot{m}_{E G R}+\dot{m}_{a i r}\right)^{2}} & =E G R \%^{2} \\
\frac{\dot{m}_{a i r}^{2}}{\left(\dot{m}_{E G R}+\dot{m}_{a i r}\right)^{2}} & =E G R \%^{2} \cdot \frac{\dot{m}_{a i r}^{2}}{\dot{m}_{E G R}^{2}} \\
\dot{m}_{E G R} & =\dot{m}_{a i r} \cdot \frac{E G R \%}{1-E G R \%}
\end{aligned}
$$

The fourth equation is found in the definition of the volumetric efficiency, which is defined as the ratio of the actual mass entering the cylinder to the theoretical mass capacity in the cylinder at a certain engine speed $n$ :

$$
\lambda_{l}=\frac{m_{\text {actual }}}{m_{\text {theor }}}=\frac{\dot{m}_{\text {actual }}}{m_{\text {theor }} \cdot n \cdot \chi}=\frac{\dot{m}_{E G R}+\dot{m}_{\text {air }}+\dot{m}_{H_{2}}}{m_{\text {theor }} \cdot n \cdot \chi}
$$

with $\chi=\frac{1}{2}$ for four-stroke engines and $m_{\text {theor }}$ depending on the actual air-fuel ratio $(\lambda)$, the amount of EGR and the cylinder volume. Neglecting $\dot{m}_{H_{2}}$ with 585 regard to $\dot{m}_{a i r}$ in this equation gives an expression for $\left(\dot{m}_{E G R}+\dot{m}_{a i r}\right)$, which is the fourth and final substitution that has to be made.

At this point, equation 19 is reshaped to a general equation of the relative error on the EGR\%:

$$
\left(\frac{\delta E G R \%}{E G R \%}\right)^{2}=\frac{1}{\left(\lambda_{l} \cdot m_{\text {theor }} \cdot n \cdot \chi\right)^{2}} \cdot\left(\frac{(1-E G R \%)^{2}}{E G R \%^{2}} \cdot \delta \dot{m}_{E G R}{ }^{2}+\delta \dot{m}_{a i r}^{2}\right)
$$

Appendix A.2. Accuracy equation of the error on the EGR\% for method 1

In Section 2.2 we found that the EGR mass rate is equal to:

$$
\dot{m}_{E G R}=\rho_{E G R} \cdot \Delta Q_{a i r}
$$

Applying Taylor on this equation and combining equation A.6 with equation 21 to eliminate $\Delta Q_{\text {air }}$ gives:

$$
\delta \dot{m}_{E G R}^{2}=\rho_{E G R}{ }^{2} \cdot \delta \Delta Q_{a i r}{ }^{2}+\frac{E G R \%^{2}}{(1-E G R \%)^{2}} \cdot \dot{m}_{a i r}^{2} \cdot \frac{\delta \rho_{E G R}{ }^{2}}{\rho_{E G R}^{2}}
$$

We identify two errors:

1. $\delta \Delta Q_{a i r}$, calculated by applying Taylor on $\Delta Q_{a i r}=Q_{a i r, 0}-Q_{a i r, 1}$ and equal to $\sqrt{2} \cdot \delta Q_{\text {air }}$. 
2. $\delta \rho_{E G R}$, the error on the density of the exhaust gases. This error is calculated by applying Taylor on equation 5 . Neglecting the temperature and pressure errors we get:

$$
\frac{\delta \rho_{E G R}}{\rho_{E G R}}=\frac{\delta R_{E G R}}{R_{E G R}}
$$

$\delta R_{E G R}$ is calculated in Appendix B and depends on the errors $\delta \dot{m}_{a i r}$ and $\delta \dot{m}_{H_{2}} ;$ consequently, $\delta \rho_{E G R}$ too.

When using the first expression of equation B.6 for the error $\delta R_{E G R}$ and by substituting equation A.8 in equation 20, we obtain an equation of the relative error on the EGR\%:

$$
\left(\frac{\delta \mathrm{EGR} \%}{E G R \%}\right)^{2}=\frac{1}{\left(\lambda_{l} \cdot m_{\text {theor }} \cdot n \cdot \chi\right)^{2}} \cdot\left(c_{1} \cdot \delta \dot{m}_{\text {air }}^{2}+c_{2} \cdot \delta \dot{m}_{H_{2}}^{2}\right)
$$

With:

$$
\begin{aligned}
& c_{1}=2 \cdot\left(\frac{\rho_{E G R}}{\rho_{\text {air }}}\right)^{2} \cdot \frac{(1-E G R \%)^{2}}{E G R \%^{2}}+1+\frac{2698.77}{\left(1+\frac{0.029}{\lambda}\right)^{4}} \cdot \frac{1}{R_{E G R}^{2}} \cdot \frac{1}{\lambda^{2}} \\
& c_{2}=\frac{2698.77 \cdot L_{s}^{2}}{\left(1+\frac{0.029}{\lambda}\right)^{4}} \cdot \frac{1}{R_{E G R}^{2}}
\end{aligned}
$$

The approach to find the influences on the error of the EGR\% for method 2 is similar to section Appendix A.2: the error $\delta \dot{m}_{E G R}^{2}$ is calculated in this section and afterwards substituted in the general equation of the relative error on the EGR\% (equation 20).

In section 2.3 we determined the EGR mass rate as:

$$
\dot{m}_{E G R}=\frac{1}{M W_{a i r}} \cdot \dot{m}_{a i r} \cdot M W_{E G R} \cdot \Delta y_{O_{2}}
$$

Applying Taylor gives:

$$
\delta \dot{m}_{E G R}^{2}=\left(\frac{M W_{E G R}}{M W_{\text {air }}}\right)^{2} \cdot\left(\Delta y_{O_{2}}^{2} \cdot \delta \dot{m}_{\text {air }}^{2}+\dot{m}_{\text {air }}^{2} \cdot \delta \Delta y_{O_{2}}^{2}+\dot{m}_{\text {air }}^{2} \cdot \Delta y_{O_{2}}^{2} \cdot \frac{\delta M W_{E G R}^{2}}{M W_{E G R}^{2}}(A \text {. }\right.
$$

We identify three errors:

1. $\delta \dot{m}_{\text {air }}$, defined by the measuring device; 
2. $\delta \Delta y_{O_{2}}$, calculated by applying Taylor on $\Delta y_{O_{2}}=\frac{y_{O 2, a i r}-y_{O 2, m i x}}{y_{O 2, m i x}-y_{O 2, E G R}}$. This calculation is written out in Appendix C;

3. $\delta M W_{E G R}$, calculated in Appendix B and depending on the errors $\delta \dot{m}_{a i r}$ and $\delta \dot{m}_{H_{2}}$.

To eliminate $\Delta y_{O_{2}}$ in equation A.10 we combine equation A.6 with equation 12. Using the first expression of equation B.5 for $\delta M W_{E G R}$, we obtain that the

$$
\left(\frac{\delta \mathrm{EGR} \%}{E G R \%}\right)^{2}=\frac{1}{\left(\lambda_{l} \cdot m_{\text {theor }} \cdot n \cdot \chi\right)^{2}} \cdot\left(c_{1} \cdot \delta \dot{m}_{\text {air }}^{2}+c_{2} \cdot \delta \dot{m}_{H_{2}}^{2}+c_{3} \cdot \delta y_{O_{2}}^{2}\right)
$$

with:

$$
\begin{aligned}
c_{1} & =\frac{2.7 \cdot 10^{-5}}{\left(1+\frac{0.21}{\lambda}\right)^{4}} \cdot \frac{1}{M W_{E G R}^{2}} \cdot \frac{1}{\lambda^{2}}+2 \\
c_{2} & =\frac{2.7 \cdot 10^{-5}}{\left(1+\frac{0.21}{\lambda}\right)^{4}} \cdot \frac{L_{s}^{2}}{M W_{E G R}^{2}} \\
c_{3} & =\frac{\dot{m}_{\text {air }}^{2}}{\left(y_{O_{2}, \text { mix }}-y_{O_{2}, E G R}\right)^{2}} \cdot\left(2+\frac{2}{x} \cdot \frac{(1-E G R \%)}{E G R \%}+\frac{1}{x^{2}} \cdot \frac{(1-E G R \%)^{2}}{E G R \% 2}\right)
\end{aligned}
$$

and $x=\frac{M W_{a i r}}{M W_{E G R}}$.

Appendix A.4. Accuracy equation of the error on the EGR\% for method 3

In Section 2.4 we determined the EGR mass rate as:

$$
\dot{m}_{E G R}=\frac{1}{M W_{\text {air }}} \cdot \dot{m}_{a i r} \cdot M W_{E G R} \cdot \Delta y_{H_{2} O}
$$

${ }_{625}$ which is similar to $\dot{m}_{E G R}$ of method 2. Consequently, applying Taylor results in similar equation as in Section Appendix A.3:

$$
\delta \dot{m}_{E G R}^{2}=\left(\frac{M W_{E G R}}{M W_{a i r}}\right)^{2} \cdot\left(\Delta y_{H_{2} O}^{2} \cdot \delta \dot{m}_{a i r}^{2}+\dot{m}_{a i r}^{2} \cdot \delta \Delta y_{H_{2} O}^{2}+\dot{m}_{a i r}^{2} \cdot \Delta y_{H_{2} O}^{2} \cdot \frac{\delta M W_{E G R}^{2}}{M W_{E G R}^{2}}(\mathbf{A} .11)\right.
$$

Three errors are identified: $\delta \dot{m}_{a i r}$ and $\delta M W_{E G R}$ which are defined as in Section Appendix A.3; and $\Delta y_{H_{2}} O$, which is calculated by applying Taylor on:

$$
\Delta y_{H_{2} O}=\frac{y_{H_{2} O, a i r}-y_{H_{2} O, m i x}}{y_{H_{2} O, m i x}-y_{H_{2} O, E G R}} .
$$

Differently from Section 3.3, $\delta \Delta y_{\mathrm{H}_{2} \mathrm{O}}$ depends on $\delta y_{\mathrm{H}_{2} \mathrm{O}}$ which is at its turn 630 calculated by applying Taylor on: 


$$
y_{\mathrm{H}_{2} \mathrm{O}}=\frac{\phi \cdot p_{s}}{p}
$$

and consequently depends on the pressure, saturation pressure and relative humidity at the places according to Figure 1. The calculations to obtain an equation for $\delta \Delta y_{\mathrm{H}_{2} \mathrm{O}}$ are described in Appendix C.

To eliminate $\Delta y_{\mathrm{H}_{2} \mathrm{O}}$ in equation A.11, we combine equation A.6 with equation 12. With all these substitutions we obtain a similar equation as in Section 3.3 for the relative error on the EGR\%, but with the error $\delta O_{2}$ replaced by $\delta y_{H_{2} O, a v}$ (as in Equation C.7) and a different coefficient $c_{3}$ :

$$
\left(\frac{\delta \mathrm{EGR} \%}{E G R \%}\right)^{2}=\frac{1}{\left(\lambda_{l} \cdot m_{\text {theor }} \cdot n \cdot \chi\right)^{2}} \cdot\left(c_{1} \cdot \delta \dot{m}_{\text {air }}^{2}+c_{2} \cdot \delta \dot{m}_{H_{2}}^{2}+c_{3} \cdot \delta y_{H_{2} O, a v}{ }^{2}\right)
$$

with:

$c_{1}=2+\frac{2.7 \cdot 10^{-5}}{\left(1+\frac{0.21}{\lambda}\right)^{4}} \cdot \frac{1}{\lambda^{2}} \cdot \frac{1}{M W_{E G R}^{2}}$

$c_{2}=\frac{2.7 \cdot 10^{-5}}{\left(1+\frac{0.21}{\lambda}\right)^{4}} \cdot \frac{L_{s}^{2}}{M W_{E G R}^{2}}$

$c_{3}=\frac{\dot{m}_{a i r}^{2}}{\left(y_{H_{2} O, m i x}-y_{H_{2} O, E G R}\right)^{2}} \cdot\left(2+\frac{2}{x} \cdot \frac{(1-E G R \%)}{E G R \%}+\frac{2}{x^{2}} \cdot \frac{(1-E G R \%)^{2}}{E G R \%^{2}}\right)$

and $x=\frac{M W_{a i r}}{M W_{E G R}}$.

\section{Appendix B. Calculation of $R_{E G R}$ and $M W_{E G R}$ and their accuracy}

The specific gas constant and molar weight of the re-circulated exhaust gases, are determined by the combustion reaction of hydrogen. As can be seen in equation 2 the main combustion products are $\mathrm{H}_{2} \mathrm{O}, \mathrm{N}_{2}$ and respectively $\mathrm{O}_{2}$ or $H_{2}$ for $\lambda \geq 1$ or $\lambda<1$. The molar weight of the exhaust gas is a function of the molar weights of its components:

$$
M W_{E G R}=\left\{\begin{array}{l}
\lambda \geq 1: y_{H_{2} O} \cdot M W_{H_{2} O}+y_{N_{2}} \cdot M W_{N_{2}}+y_{O_{2}} \cdot M W_{O_{2}} \\
\lambda<1: y_{H_{2} O} \cdot M W_{H_{2} O}+y_{N_{2}} \cdot M W_{N_{2}}+y_{H_{2}} \cdot M W_{H_{2}}
\end{array}\right.
$$

with y the mole fraction of the subscripted gas, calculated out of the combustion reaction. The specific gas constant is calculated analogously, except according to the units of $\mathrm{R}$, mass fractions instead of mole fractions are used:

$$
R_{E G R}=\left\{\begin{array}{l}
\lambda \geq 1: c_{\mathrm{H}_{2} \mathrm{O}} \cdot R_{\mathrm{H}_{2} \mathrm{O}}+c_{\mathrm{N}_{2}} \cdot R_{N_{2}}+c_{\mathrm{O}_{2}} \cdot R_{\mathrm{O}_{2}} \\
\lambda<1: c_{\mathrm{H}_{2} \mathrm{O}} \cdot R_{\mathrm{H}_{2} \mathrm{O}}+c_{N_{2}} \cdot R_{N_{2}}+c_{H_{2}} \cdot R_{H_{2}}
\end{array}\right.
$$


Calculating the molar weight and the specific gas constant of the exhaust gases

$$
\begin{gathered}
M W_{E G R}=\left\{\begin{array}{l}
\lambda \geq 1: \frac{5.12 \cdot \lambda+0.15}{177.41 \cdot \lambda+37.12} \\
\lambda<1: \frac{0.26 \cdot \lambda+0.21}{12.53 \cdot \lambda+6.63}
\end{array}\right. \\
R_{E G R}=\left\{\begin{array}{l}
\lambda \geq 1: \frac{1774.15 \cdot \lambda+371.16}{6.15 \cdot \lambda+0.18} \\
\lambda<1: \frac{14029.87 \cdot \lambda+7423.21}{34.75 \cdot \lambda+28.57}
\end{array}\right.
\end{gathered}
$$

With $\lambda$ defined by equation A.1 and applying equation 17 on $M W_{E G R}$ and $R_{E G R}$, we obtain the absolute errors on $M W_{E G R}$ and $R_{E G R}$, squared:

$$
\begin{gathered}
\delta M W_{E G R}^{2}=\left\{\begin{array}{l}
\lambda \geq 1: \frac{2.7 \cdot 10^{-5} \cdot L_{s}^{2}}{\left(1+\frac{0.21}{\lambda}\right)^{4}} \cdot \frac{1}{\dot{m}_{a i r}^{2}} \cdot\left(\frac{1}{\left(\lambda \cdot L_{s}\right)^{2}} \cdot \delta \dot{m}_{\text {air }}^{2}+\delta \dot{m}_{H_{2}}^{2}\right) \\
\lambda<1: \frac{3.63 \cdot 10^{-5} \cdot L_{s}^{2}}{\left(1+\frac{0.53}{\lambda}\right)^{4}} \cdot \frac{1}{\dot{m}_{a i r}^{2}} \cdot\left(\frac{1}{\left(\lambda \cdot L_{s}\right)^{2}} \cdot \delta \dot{m}_{a i r}^{2}+\delta \dot{m}_{H_{2}}^{2}\right)
\end{array}\right. \\
\delta R_{E G R}^{2}=\left\{\begin{array}{l}
\lambda \geq 1: \frac{2698.77 \cdot L_{s}^{2}}{\left(1+\frac{0.029}{\lambda}\right)^{4}} \cdot \frac{1}{\dot{m}_{a i r}^{2}} \cdot\left(\frac{1}{\left(\lambda \cdot L_{s}\right)^{2}} \cdot \delta \dot{m}_{\text {air }}^{2}+\delta \dot{m}_{H_{2}}^{2}\right) \\
\lambda<1: \frac{14003.16 \cdot L_{s}^{2}}{\left(1+\frac{0.822}{\lambda}\right)^{4}} \cdot \frac{1}{\dot{m}_{a i r}^{2}} \cdot\left(\frac{1}{\left(\lambda \cdot L_{s}\right)^{2}} \cdot \delta \dot{m}_{\text {air }}^{2}+\delta \dot{m}_{H_{2}}^{2}\right.
\end{array}\right)
\end{gathered}
$$

\section{Appendix C. Calculating the absolute error on $\Delta y_{\mathrm{O}_{2}}$ and $\Delta y_{\mathrm{H}_{2} \mathrm{O}}$}

This first part of this appendix section will deal with the simplification of the error on $\Delta y_{O_{2}}$ which is defined as:

$$
\Delta y_{O_{2}}=\frac{O_{2, a i r}-O_{2, m i x}}{O_{2, m i x}-O_{2, E G R}}
$$

Applying Taylor on C.1 gives the error on $\Delta y_{O_{2}}$ :

$$
\delta \Delta y_{O_{2}}{ }^{2}=\frac{1}{\left(O_{2, \text { mix }}-O_{2, E G R}\right)^{2}} \cdot\left(\left(\Delta y_{O_{2}}+1\right)^{2}+\Delta y_{O_{2}}^{2}\right) \cdot \delta O_{2}{ }^{2}
$$

with $\delta \mathrm{O}_{2}$ the error of the oxygen measuring device. Combining equation A.6

$$
\Delta y_{O_{2}}=\frac{M W_{\text {air }}}{M W_{E G R}} \cdot \frac{E G R \%}{1-E G R \%}=x \cdot \frac{E G R \%}{1-E G R \%}
$$

with $x=\frac{M W_{a i r}}{M W_{E G R}}$. Substituting equation C.3 in equation C.2 gives the expression for the absolute error on $\Delta y_{O_{2}}$ :

$$
\delta \Delta y_{O_{2}}{ }^{2}=2 \cdot\left(x^{2} \cdot \frac{(E G R \%)^{2}}{(1-E G R \%)^{2}}+x \cdot \frac{E G R \%}{(1-E G R \%)}+\frac{1}{2}\right) \cdot \frac{\delta O_{2}{ }^{2}}{\left(O_{2, \operatorname{mix}}-O_{2, E G R}\right)^{2}}
$$


The second part of this appendix section deals with the simplification of the error on $\Delta y_{\mathrm{H}_{2} \mathrm{O}}$, which is calculated analogously as $\delta \Delta y_{\mathrm{O}_{2}}$ :

$$
\delta \Delta y_{\mathrm{H}_{2} \mathrm{O}}{ }^{2}=\frac{\left(\delta y_{\mathrm{H}_{2} \mathrm{O}, \text { air }}^{2}+\Delta y_{\mathrm{H}_{2} \mathrm{O}}^{2} \cdot \delta y_{\mathrm{H}_{2} \mathrm{O}, \mathrm{EGR}}^{2}+\left(\Delta y_{\mathrm{H}_{2} \mathrm{O}}+1\right)^{2} \cdot \delta y_{\mathrm{H}_{2} \mathrm{O}, \text { pix }}^{2} .5\right)}{\left(y_{\mathrm{H}_{2} \mathrm{O}, \text { mix }}-y_{\mathrm{H}_{2} \mathrm{O}, \mathrm{EGR}}\right)^{2}}
$$

However, the difference between equation C.2 and C.5 is that $\delta y_{\mathrm{H}_{2} \mathrm{O}}$ depends on the pressure, saturation pressure, relative humidity and their errors through equation A.13:

$$
\delta y_{H_{2} O}^{2}=\frac{1}{p^{2}} \cdot\left(p_{s}^{2} \cdot \delta \phi^{2}+\phi^{2} \cdot \delta p_{s}^{2}+\left(\frac{\phi \cdot p_{s}}{p}\right)^{2} \cdot \delta p^{2}\right)^{2}
$$

If we define $\delta y_{\mathrm{H}_{2} \mathrm{O}, \mathrm{av}}^{2}$, the average error on the mole fractions of $\mathrm{H}_{2} \mathrm{O}$, as:

$$
\delta y_{\mathrm{H}_{2} \mathrm{O}, \mathrm{av}}^{2}=\frac{1}{3} \cdot\left(\delta y_{\mathrm{H}_{2} \mathrm{O}, \mathrm{air}}^{2}+\delta y_{\mathrm{H}_{2} \mathrm{O}, \mathrm{EGR}}^{2}+\delta y_{\mathrm{H}_{2} \mathrm{O}, \mathrm{mix}}^{2}\right)
$$

we can write equation C.5 similar to equation C.4:

$$
\delta \Delta y_{H_{2} O} \mathrm{O}^{2}=2 \cdot\left(x^{2} \frac{(E G R \%)^{2}}{(1-E G R \%)^{2}}+x \frac{E G R \%}{(1-E G R \%)}+1\right) \cdot \frac{\delta y_{H_{2} O, a v}^{2}}{\left(y_{H_{2} O, m i x}-y_{H_{2} O, E G R}\right)^{2}}
$$

\section{Appendix D. Determination of the offset between method 1 and method 2 in Figure 5}

The reason for the offset in Figure 5 can be explained by taken the ratio of the EGR rate of method 1 (equation 3):

$$
\dot{m}_{E G R, \text { method } 1}=\rho_{E G R} \cdot \Delta Q_{\text {air }}
$$

and the EGR rate of the second method (equation 12):

$$
\dot{m}_{E G R, \text { method } 2}=\frac{1}{M W_{\text {air }}} \cdot \dot{m}_{\text {air }} \cdot M W_{E G R} \cdot \Delta y_{O_{2}}
$$

Therefore equation D.1 is written as:

$$
\dot{m}_{E G R, \operatorname{method} 1}=\frac{\rho_{E G R}}{\rho_{a i r}} \cdot \dot{m}_{a i r, 1} \cdot\left(\frac{\dot{m}_{a i r, 0}}{\dot{m}_{a i r, 1}}-1\right)
$$

with $\dot{m}_{a i r, 0}$ and $\dot{m}_{a i r, 1}$ respectively the EGR mass rate without use of EGR and with use of EGR. We obtain for the ratio:

$$
\frac{\dot{m}_{E G R, \text { method } 1}}{\dot{m}_{E G R, \text { method } 2}}=\left(\frac{\dot{m}_{\text {air }, 0}}{\dot{m}_{\text {air }, 1}}-1\right) \cdot \frac{1}{\Delta y_{O_{2}}} \cdot\left(\frac{\rho_{E G R} \cdot M W_{\text {air }}}{\rho_{\text {air }} \cdot M W_{E G R}}\right)
$$

We see from equation D.4 that the offset between the EGR rate (and by consequence the EGR\% too) of method 1 and 2 depends on the variables of each method. Consequently, there will always be an offset, unless the variables are neutralized by each other. 
Appendix E. Experimental conditions

\begin{tabular}{|c|c|c|c|c|c|c|c|c|}
\hline no. & $\begin{array}{c}\text { speed } \\
{[\mathrm{rpm}]}\end{array}$ & $\lambda$ & $\begin{array}{c}\mathbf{p}_{\text {gauge }} \\
\text { [bar] }\end{array}$ & $\begin{array}{c}\text { ignition } \\
{\left[{ }^{\circ} \text { ca BTDC }\right]}\end{array}$ & $\begin{array}{l}\text { torque } \\
{[\mathrm{Nm}]}\end{array}$ & $\begin{array}{c}\text { BMEP } \\
\text { [bar] }\end{array}$ & $\begin{array}{l}\text { EGR\% } \\
\text { method } 1\end{array}$ & $\begin{array}{c}\text { EGR\% } \\
\text { method } 2\end{array}$ \\
\hline 1 & 1800 & 0.97 & 0.0 & -4 & 13.8 & 4.26 & $41.6 \%$ & $47.0 \%$ \\
\hline 2 & 1800 & 0.97 & 0.0 & -4 & 15.2 & 4.69 & $34.2 \%$ & $45.8 \%$ \\
\hline 3 & 2250 & 1.00 & 0.0 & -7 & 16.0 & 4.94 & $30.7 \%$ & $36.9 \%$ \\
\hline 4 & 3000 & 1.00 & 0.0 & -7 & 14.9 & 4.60 & $30.9 \%$ & $34.5 \%$ \\
\hline 5 & 2750 & 0.99 & 0.0 & -7 & 13.1 & 4.04 & $31.0 \%$ & $33.9 \%$ \\
\hline 6 & 2000 & 0.99 & 0.0 & -6 & 16.3 & 5.03 & $29.1 \%$ & $32.9 \%$ \\
\hline 7 & 2000 & 0.98 & 0.0 & -6 & 16.7 & 5.15 & $25.3 \%$ & $28.9 \%$ \\
\hline 8 & 1800 & 0.97 & 0.5 & -5 & 31.6 & 9.75 & $24.2 \%$ & $27.1 \%$ \\
\hline 9 & 3000 & 0.97 & 0.7 & -9 & 38.8 & 11.97 & $22.7 \%$ & $26.5 \%$ \\
\hline 10 & 2250 & 0.97 & 0.5 & -5 & 34.8 & 10.74 & $10.1 \%$ & $18.4 \%$ \\
\hline 11 & 3000 & 0.97 & 0.5 & -7 & 34.8 & 10.74 & $4.8 \%$ & $12.7 \%$ \\
\hline 12 & 2250 & 0.97 & 0.7 & -9 & 39.9 & 12.31 & $4.9 \%$ & $6.4 \%$ \\
\hline no. & $\begin{array}{c}\text { speed } \\
{[\mathrm{rpm}]}\end{array}$ & $\lambda$ & $\begin{array}{c}\mathbf{p}_{\text {gauge }} \\
\text { [bar] }\end{array}$ & $\begin{array}{c}\text { ignition } \\
{\left[\begin{array}{l}0 \\
\text { ca BTDC }]\end{array}\right.}\end{array}$ & $\begin{array}{l}\text { torque } \\
{[\mathrm{Nm}]}\end{array}$ & $\begin{array}{c}\text { BMEP } \\
\text { [bar] }\end{array}$ & $\begin{array}{c}\text { EGR\% } \\
\text { method 2(a) }\end{array}$ & $\begin{array}{c}\text { EGR\% } \\
\text { method 2(b) }\end{array}$ \\
\hline 14 & 2000 & 1.01 & 0.0 & -4 & 12.9 & 3.98 & $44.1 \%$ & $42.8 \%$ \\
\hline 15 & 2000 & 1.29 & 0.0 & -4 & 8.3 & 2.56 & $40.4 \%$ & $36.5 \%$ \\
\hline 16 & 1500 & 1.05 & 0.0 & -6 & 13.3 & 4.10 & $38.1 \%$ & $46.4 \%$ \\
\hline 17 & 1500 & 1.00 & 0.0 & -6 & 16.9 & 5.21 & $27.8 \%$ & $29.6 \%$ \\
\hline 18 & 2000 & 1.31 & 0.0 & -4 & 13.6 & 4.20 & $19.8 \%$ & $26.2 \%$ \\
\hline 19 & 1500 & 1.02 & 0.0 & -6 & 18.2 & 5.62 & $19.8 \%$ & $25.3 \%$ \\
\hline 20 & 1500 & 1.25 & 0.0 & -6 & 13.7 & 4.23 & $17.7 \%$ & $28.2 \%$ \\
\hline 21 & 2000 & 1.70 & 0.0 & -4 & 10.4 & 3.21 & $7.7 \%$ & $7.4 \%$ \\
\hline 22 & 2000 & 1.60 & 0.0 & -4 & 13.5 & 4.17 & $6.8 \%$ & $19.1 \%$ \\
\hline 23 & 1500 & 1.19 & 0.0 & -6 & 17.8 & 5.49 & $6.5 \%$ & $10.5 \%$ \\
\hline 24 & 2000 & 1.92 & 0.0 & -4 & 10.8 & 3.33 & $6.4 \%$ & $11.1 \%$ \\
\hline 25 & 1500 & 1.61 & 0.0 & -6 & 13.9 & 4.29 & $4.8 \%$ & $10.5 \%$ \\
\hline
\end{tabular}

Table E.3: Experimental conditions 